\title{
Genuine Selective Caspase-2 Inhibition with new Irreversible Small Peptidomimetics
}

Elodie Bosc ${ }^{1}$, Julie Anastasie ${ }^{1}$, Feryel Soualmia ${ }^{1}$, Pascale Coric ${ }^{2}$, Ju Youn $\mathrm{Kim}^{3}$, Gullen Lacin $^{1,4}$, Eric Duplus ${ }^{1}$, Philippe Tixador ${ }^{1}$, Bernard Brugg ${ }^{1}$, Michelle Reboud-Ravaux ${ }^{1}$, Serge Bouaziz ${ }^{2}$, Michael Karin ${ }^{3}$, Chahrazade El Amri ${ }^{1}$, and Etienne Jacotot ${ }^{1,5,6}$

1 INSERM U1164, CNRS UMR 8256, Sorbonne Université, Campus Pierre et Marie Curie, Paris F-75005, France.

2 Université de Paris, CNRS, CiTCoM, F-75006 Paris, France.

3 Laboratory of Gene Regulation and Signal Transduction, Departments of Pharmacology and Pathology, University of California San Diego, School of Medicine, La Jolla, CA 92093, USA

4 MicroBrain Biotech S.A.S. 52 Avenue de l'Europe Marly-Le-Roi, F-78160, France.

5 Taub Institute for Research on Alzheimer's Disease and the Aging Brain, Columbia University, New York, NY, United States

6 Department of Pathology and Cell Biology, Columbia University, New York, NY, United States

\section{Correspondence should be addressed to:}

Prof Etienne D. Jacotot, PhD

Department of Pathology \& Cell Biology,

Taub Institute for Research on Alzheimer's Disease and the Aging Brain

Columbia University Medical Center,

New York, New York 10033.

E-mail: edj2122@cumc.columbia.edu

E-mail: etienne.jacotot@inserm.fr

\section{Condensed Title}

Selective Caspase-2 inhibition with novel small peptidomimetics 


\section{Abstract}

Caspase-2 (Casp2) is a promising therapeutic target in several human diseases including nonalcoholic steatohepatitis (NASH) and Alzheimer's disease (AD). However, the design of active-site-directed inhibitor selective to individual caspase family members is challenging because caspases have extremely similar active sites. Here we present new peptidomimetics derived from the VDVAD pentapeptide structure, harboring non-natural modifications at the P2 position and an irreversible warhead. Enzyme kinetics shows that these new compounds, such as LJ2 or its specific isomer LJ2a, and LJ3a, strongly and irreversibly inhibit Casp2 with genuine selectivity. According to Casp2 role in cellular stress responses, LJ2 inhibits cell death induced by microtubule destabilization or hydroxamic acid-based deacetylase inhibition. The most potent peptidomimetic, LJ2a, inhibits human Casp2 with a remarkably high inactivation rate $\left(\mathrm{k}_{3} / \mathrm{K}_{\mathrm{i}} \sim 5500000 \mathrm{M}^{-1} \mathrm{~s}^{-1}\right)$ and the most selective inhibitor, LJ3a, has a near to 1000 times higher inactivation rate on Casp2 as compared to Casp3. Structural analysis of LJ3a shows that spatial configuration of $\mathrm{C}_{\alpha}$ at the $\mathrm{P} 2$ position determines inhibitor efficacy. In transfected human cell lines overexpressing site-1 protease (S1P), sterol regulatory element-binding protein 2 (SREBP2) and Casp2, LJ2a and LJ3a fully inhibit SREBP2 activation, suggesting a potential to prevent NASH development. Furthermore, in primary hippocampal neurons treated with $\beta$-amyloid oligomers, submicromolar concentrations of LJ2a and of LJ3a prevent synapse loss, indicating a potential for further investigations in AD treatment.

Key words: Caspase-2, irreversible inhibitors, peptidomimetics, drug design, cell death, synapse loss, steatohepatitis, Alzheimer's Disease 


\section{Introduction}

Cysteine-dependent aspartate-specific proteases (Caspases) are a family of cysteine endoproteases (C14A family, CD clan), unique to the animal kingdom [1], and are well known as central effectors and regulators of apoptosis and inflammation [2]. They are also involved in the regulation of non-apoptotic cell death pathways, as well as in various physiological processes which include proliferation, differentiation, cell migration, several functions of the nervous system (e.g., synaptic plasticity, axonal guidance, long-term potentiation, pruning of dendritic spines), cell cycle control, and stress responses [3]. These functions are critical and indicate that Caspases are therapeutic targets of great interest for several diseases $[4,5,6]$.

Caspase-2 (Casp2, Nedd2, Ich1), the most evolutionary conserved member of the Caspase family, has numerous interesting properties and functions, which suggest that its specific targeting could lead to high potential drug candidates [7, 8]. First, it is non-essential for physiological programmed cell death [9] whereas it mediates stress-induced and pathologically induced apoptosis [10]. Casp2 is involved in the response to a wide panel of stresses (endogenous, infectious, physicochemical, xenobiotic, metabolic, inflammatory) by initiating apoptotic cell death pathways, by repressing autophagy, or by activating the inflammasome [7-10]. At the hepatic level, Casp2 plays an essential role in the pathogenesis of non-alcoholic steatohepatitis (NASH) [11, 12]. Within the nervous system, it is involved in synaptic plasticity and cognitive flexibility [13], and several neuropathological mechanisms such as neonatal brain damage [14], retinal ischemia [15], the synaptotoxic effects of $\beta$-amyloid peptide [16, 17], and tauopathies [18]. Casp2 is required for the cognitive decline seen in human amyloid precursor protein transgenic mice and experiments with Casp2 deficient mice implicate Casp2 as key driver of synaptic dysfunction in AD [17]. Consequently, there is a need to design Casp2 selective inhibitors (or substrates) to precisely define its apoptotic and nonapoptotic roles and to interfere pharmacologically with disease-related pathways.

Caspases cleave peptides and proteins after an Asp (P1 position) [1]. This unique property among cysteine-proteases, has led to the development of hundreds of active sitedirected small peptides and peptidomimetics that are Caspase-specific [19]. Indeed, medicinal 
chemistry of Caspase inhibitors led to potent druggable peptide derivatives (e.g., Q-VD-OPh, an irreversible pan-caspase inhibitor [20]), to the clinical development of potent peptidomimetics (e.g., Belnacasan/VX765 [21], a reversible inhibitor of inflammatory caspases), and to the advanced clinical development of safe broad-spectrum caspase inhibitor (e.g., Emricasan [22], an irreversible pan-caspase inhibitor) [23]. However, the design of active site-directed inhibitors selective of one given individual Caspase is highly challenging because caspases have similar active sites, and most $A s p^{\mathrm{P} 1}$-containing small peptides are efficiently recognized by several caspases [24]. This is even more critical when designing Casp2 inhibitors, as Casp2 and Caspase-3 (Casp3) share highly similar features regarding their active sites and inhibition by synthetic substrates $[25,26]$. Studies with synthetic peptides containing C-terminal reversible (aldehyde; $\mathrm{CHO}$ ) or irreversible (fluoromethylketone; fmk) warheads have established that Casp2, Casp3, and Casp7 preferentially cleave substrate having the general structure $\mathrm{X}^{\mathrm{P} 5}-\mathrm{Asp}^{\mathrm{P4}}-\mathrm{X}^{\mathrm{P} 3}-\mathrm{X}^{\mathrm{P} 2}-\mathrm{Asp}^{\mathrm{P} 1}-\mathrm{CHO} / \mathrm{fmk}$ (with relative permissivity at $\mathrm{P} 5, \mathrm{P} 3$ and P2), whereas other Caspases poorly recognize Asp ${ }^{\text {P4 }}$-containing peptides [27-29]. Casp2 requires the presence of a P5 residue to recognize peptide substrates whereas Casp3 and Casp7 do not $[19,29]$. Accordingly, the well-defined pentapeptide-based inhibitors of Casp2 (i.e., Ac-VDVAD-CHO, z-VDVAD-fmk, Q-VDVAD-OPh) are also efficient inhibitors of Casp3 $[30,31]$.

Using structural information on the Casp2 and Casp3 active sites and molecular modeling, Maillard et al., identified that the replacement of Alanine (P2 position), in the nonselective Ac-VDVAD-CHO peptide, by bulky residues, for instance a substituted isoquinoline or a 3-(S)-substituted proline, resulted in peptides with 20 to 60 -fold increased selectivity for Casp-2 [32].

We further elaborated from the Maillard and coworkers' approach and designed a pentapeptide derivative, named LJ2, which combined a N-terminal quinolyl-carbonyl and a Cterminal difluorophenoxymethylketone warhead with the Casp2-preferred pentapeptide backbone VDVAD where the Ala in position P2 was replaced by a substituted isoquinoline [33]. Afterward, using a hybrid combinatorial peptide substrate library, Poreba et al reported a 
peptidomimetic series having the general structure $X^{P 5}-G^{P 4}-X^{P 3}-S^{P} r^{P 2}-A s p^{P 1}-O P h$ where $X^{P 3}$ is a substituted Thr (O-benzyl-L-allothreonine), and $X^{P 5}$ is a 2-carboxy-indoline [34]. However, these irreversible inhibitors showed significant but still moderate selectivity for Casp2, as the best compound of the series, $\mathrm{NH}-23-\mathrm{C} 2$, showed $\mathrm{K}_{\mathrm{obs}} / \mathrm{I}$ ratio vis-a-vis Casp3 being $\sim 32$ times lower than for Casp2) [34].

Here we present the structure and characterization of irreversible peptidomimetics having the general structure Quinadoyl-Val ${ }^{\mathrm{P5}}-\mathrm{Asp}^{\mathrm{P4}}-\mathrm{Val}^{\mathrm{P3}}-\mathrm{X}^{\mathrm{P2}}-\mathrm{Asp} \mathrm{P}^{\mathrm{P} 1}$-difluorophenoxy-methylketone, with $\mathrm{X}^{\mathrm{P} 2}$ being either 6-methyl-tetrahydro-isoquinoline (LJ2, LJ2a, and LJ2b) or a 3(S)-neopentyl proline (LJ3a). Kinetics using recombinant human Casp2 and Casp3 show that, these inhibitors have very strong off-rate $(\mathrm{k} 3 / \mathrm{Ki})$ and selectivity toward Casp2. Particularly, LJ3a is highly selective for Casp2 (946 times less efficient on Casp3), far above previously described Casp2 inhibitors $[32,34]$. We further show that these potent and selective Casp2 inhibitors have strong effects in several biological models including protection against cell death induced by microtubule destabilization, blockage of Casp2- and S1P-mediated SREBP2 activation and inhibition of synapse loss in primary neurons treated with $\beta$-amyloid oligomers. 


\section{Materials and methods}

Enzymes, substrates, and inhibitors

The human active recombinants caspase-2 (\#ALX-201-057), caspase-6 (\#BML-SE170), and caspase-1 (\#ALX-201-056) were purchased from Enzo Life sciences, Inc (New York, USA). The human active recombinant Caspase-3 (\#707-C3) was purchased from R\&D Systems (Minneapolis, USA). Purified Human active Cathepsin-B (\#BML-SE198), Cathepsin-D (\#BMLSE199), and Cathepsin-L (\#BML-SE201) were purchased from Enzo Life sciences. The human active Plasmin, Thrombin, and Trypsin were purchased from Sigma-Aldrich. Human Kallikrein-1 (\#2337-SE-010), Kallikrein-6 (\#5164-SE-010), Kallikrein-8/Neuropsin Protein (\#2025-SE-010) were purchased from R\&D systems. Stock solutions were stored at $-80^{\circ} \mathrm{C}$. The fluorogenic substrates Ac-VDVAD-AMC, Ac-DEVD-AMC, Ac-VEID-AMC, z-RR-AMC, RLR-AMC and the FRET substrate Phe-Arg-Leu-Lys(Dnp)-D-Arg-NH2, as well as the reversible Inhibitors, Ac-DEVD-CHO (\#ALX-260-030) and Ac-VDVAD-CHO (\#ALX-260-058) were purchased from Enzo Life sciences, Inc (New York, USA). The fluorogenic substrates Boc-QAR-AMC and Boc-VPR-AMC were purchased from Bachem AG (Bubendorf, Switzerland). The compounds c33, h33, k33, and q33 were obtained from Dr Michel Maillard, CHDI Foundation, Inc. (New York, NY). Broad spectrum inhibitors, z-VAD(Ome)-fmk (\#FK009), z-VAD-fmk (\#FK109), Q-VD-OPh (\#03OPH109-CF), were purchased from MP Biomedical (Santa Ana, USA). Q-VE-OPh (\#A0007) was purchased from Apoptrol LLC (Beavercreek, Ohio, USA) and Emricasan (\#510230), also known as IDN 6556 and PF 03491390, was obtained from Medkoo Biosciences (Morrisville, NC, USA). TRP601 $\left(\mathrm{C}_{40} \mathrm{H}_{48} \mathrm{~F}_{2} \mathrm{~N}_{6} \mathrm{O}_{11} ; \mathrm{MW}: 826.84\right)$ and $\triangle 2 \mathrm{Me}-\mathrm{TRP} 601\left(\mathrm{C}_{38} \mathrm{H}_{44} \mathrm{~F}_{2} \mathrm{~N}_{6} \mathrm{O}_{11} ; \mathrm{MW}: 798.79\right)$ were provided by Chiesi Parmaceuticals [31]. TRP801 (Q-LETD(OMe)-OPh) (MW: 771.76) was customsynthetized by Polypeptides Laboratories (Strasbourg, France) [31]. LJ2 was purchased (custom-synthesis) from by Polypeptides Laboratories (Strasbourg, France). LJ2a, LJ2b, LJ3a, and LJ3b were purchased (custom synthesis) from Bachem Americas, Inc. (Vista, CA, USA). Caspase inhibitors were solubilized in DMSO at $10 \mathrm{mM}$ and stored at $-80^{\circ} \mathrm{C}$.

In vitro Caspases activity and Inhibition assays

Caspase activities were determined by monitoring the hydrolysis of appropriate fluorogenic substrates, in 96 wells plates using a BMG Fluostar microplate reader, as a function of time at $37^{\circ} \mathrm{C}$ in the presence of untreated caspase (control) or enzyme that had been incubated with a test compound. Substrates and compounds were previously dissolved in DMSO at $10 \mathrm{mM}$, 
with final solvent concentration kept constant at lower $4 \%(v / v)$. Initial velocity $\left(V_{0}\right)$ was determined from the linear portion of the progress curve. The composition of the activity buffer was: 20 mM HEPES, pH 7.4; 0,1 \%CHAPS, 5 mM DTT, 2 mM EDTA; 800 mM sodium succinate for Caspase-2 (0.2 nM) with $25 \mu \mathrm{M}$ of Ac-VDVAD-Amino-methylcoumarin (AMC) and 20 mM HEPES, pH 7.4; 0,1 \%CHAPS, 5 mM DTT, 2 mM EDTA; supplemented with 1 $\mathrm{mg} / \mathrm{mL}$ of stabilizing agent BSA for Caspase-3 (0.1 nM) with $10 \mu \mathrm{M}$ of Ac-DEVD-AMC. Compounds $(0.001-100 \mu \mathrm{M})$ were tested in duplicate for each inhibitor concentration to detect their inhibitory potential. Enzyme and compounds were incubated for $30 \mathrm{~min}$ before to initiate enzymatic reaction by adding substrate. Initial rates determined in control experiments $\left(\mathrm{V}_{0}\right)$ were considered as $100 \%$ of the caspase activity; initial rates that were below $100 \%$ in the presence of tested compound $\left(\mathrm{V}_{\mathrm{i}}\right)$ were considered as inhibition. The inhibitory activity of compounds was expressed as $\mathrm{IC}_{50}$ (Inhibitor concentration giving $50 \%$ inhibition). The values of $\mathrm{IC}_{50}$ were calculated by fitting the experimental data using Mars data Analysis 2.0 and KaleidaGraph softwares.

$$
\% \text { Inhibition }=100\left(1-\left(\mathrm{V}_{\mathrm{i}} / \mathrm{V}_{0}\right)=100[\mathrm{I}]_{0} /\left(\mathrm{IC} \mathrm{C}_{50}+[\mathrm{I}]_{0}\right)\right.
$$

\section{Enzyme Mechanistic Studies}

For noncovalent (reversible) inhibitors, the mechanisms of inhibition were determined by varying substrate and inhibitor concentrations and using Lineweaver-Burk representations. For suicide inhibitors, inactivation can be represented by the minimum kinetic scheme (eq 2), where $E$ and $I$ are the free forms of enzyme and inhibitor, $E^{*} I$ a kinetic chimera of the Michaelis complex and E-I the covalent complex or inactivated enzyme.

$$
\mathrm{E}+\mathrm{I} \rightleftarrows \mathrm{E} * \mathrm{I} \stackrel{k 3}{\rightarrow} \mathrm{E}-\mathrm{I}
$$

$\mathrm{K}_{\mathrm{I}}$ and $\mathrm{k}_{3}$ are the kinetic constants characterizing the inactivation process and the $k_{3} / \mathrm{K}_{1}$ ratio is an index of the inhibitory potency. First-order rate constant, $\mathrm{k}_{3}$, and dissociation constant, $\mathrm{K}_{\mathrm{l}}$, were determined for Caspase-2 et -3 using the progress curve method [35]. Briefly, the enzyme activities were measured continuously for $120 \mathrm{~min}$. To determine the kinetic parameter, progress curves were obtained at several inhibition concentrations using fixed substrate concentration. Product released for each inhibitor concentrations was plotted versus time following eq 3 where the constant $\pi$ depended on [I]', a modified inhibitor concentration due to substrate competition, according to eq 4. [I]' is defined by eq 5 , where $\mathrm{K}_{\mathrm{M}}$ was Michaelis constant for the enzymatic hydrolysis of the appropriate fluorogenic substrate. The ratio $k_{i} / K_{1}$ 
was obtained by fitting the experimental data to the equations (F.U., fluorescence unit):

$$
\begin{aligned}
& F . U .=\int_{0}^{t} v i d t+F . U 0 \frac{-v o \times e^{-\pi \times t}}{\pi}+F . U .0 \\
& \pi=\frac{k i \times[I] \prime}{K I+[I] \prime} \\
& {[I]^{\prime}=\frac{[I]}{1+[S] / K M}}
\end{aligned}
$$

Linear and nonlinear regression fits of the experimental data to the equations were performed with KaleidaGraph software. The experimental conditions were [Caspase-2] $]_{0}=0.2 \mathrm{nM}$, [AcVDVAD-AMC $]_{0}=25 \mu \mathrm{M}$ and $[\text { Caspase-3 }]_{0}=0.1 \mathrm{nM},[\text { Ac-DEVD-AMC }]_{0}=10 \mu \mathrm{M} ;[]_{0}=0-100$ $\mu \mathrm{M}$.

\section{Cell lines and cell death modulation}

HeLa cells (obtained from ATCC) were cultured in Dulbecco's Modified Eagle Medium (DMEM, High Glucose, GlutaMAX ${ }^{\mathrm{TM}}$, Pyruvate) supplemented with antibiotics and 10\% FCS (Gibco, Life technologies) and maintained in T75 Flasks at $1 \times 10^{6}$ cells per flask. $24 \mathrm{~h}$ before treatments HeLa cells were transferred to 6 -well plates $\left(8 \times 10^{4}\right.$ cells/well). The lymphoblastoid cell line Molt4cl8 was a gift from Dr Bernard Krust (Inserm, University Paris 5) and was cultured in RPMI 1640 Glutamax medium supplemented with Hepes, antibiotics, and 10\% FCS. HEK293 cells were obtained from ATCC (CRL-1573) and cultured in DMEM with Glutamax and 25 mM glucose (Life Technologies) supplemented with 10\% fetal calf serum (FCS) and antibiotics. For cell death induction, the following agents were added to cell cultures: Vincristine (Sigma) and Panobistat (LBH589; Selleck). Cell death was analyzed using fluorescence microscopy (Axio-observer Z1, Zeiss; equipped with CCD camera CoolsnapHQ2, Ropert Scientific) and cytofluorometry (MACSQuant $\AA$ VYB ; Miltenyi Biotec, Bergisch Gladbach, Germany) after labelling with propidium iodide $\left(1 \mu \mathrm{g} / \mathrm{mL} ; 10 \mathrm{~min} ; 37^{\circ} \mathrm{C}\right.$; Life Technologies) and Hoechst 33342 $(1 \mu \mathrm{g} / \mathrm{mL} ; 5 \mathrm{~min} ; \mathrm{RT}$; Sigma).

\section{$\beta$-Amyloid preparation}

Lyophilized and HPLC-purified Human $\beta$-Amyloid ${ }_{1-42}\left(A \beta_{1-42}\right)$ peptide was purchased from Tocris (\#1428). 1,1,1,3,3,3-Hexafluoro-2-propanol (HFIP) was purchased from Sigma Aldrich (Germany). Oligomeric and non-oligomeric form of $A \beta_{1-42}$ peptide were produced according to ref [36]. Briefly, lyophilized peptides were solubilized at $1 \mathrm{mM}$ in 1,1,1,3,3,3-Hexafluoro-2propanol (HFIP). After $30 \mathrm{~min}$ of incubation at room temperature, HFIP was evaporated overnight and peptides were dried (Speed Vac, $1 \mathrm{~h} 4^{\circ} \mathrm{C}$ ). Then, $A \beta$ peptide stock solution was obtained by solubilization at $5 \mathrm{mM}$ in DMSO followed by bath sonication for $10 \mathrm{~min}$. To obtain 
oligomers, $A \beta_{1-42}$ stock solution was diluted to $100 \mu \mathrm{M}$ in phenol free DMEM-F12 medium and then incubated at $4^{\circ} \mathrm{C}, 24 \mathrm{~h}$. Non-oligomeric form was obtained by diluting $A \beta_{1-42}$ stock solution in fresh milliQ water.

\section{Fluidic microsystems}

Microfluidic chips were produced by standard molding methods [37] using epoxy-based negative photoresists (SU-8) and MicroBrain Biotech proprietary microdesigns (Brainies ${ }^{\mathrm{TM}}$, Cat\#: MBBT4 and MBBT5; Marly le Roi, France). Briefly, Polydimethylsiloxane (Sylgard 184, PDMS; Dow Corning, MI, USA) was mixed with curing agent (9:1 ratio) and degassed under vacuum. The resulting preparation was poured onto a chosen SU8 mold and reticulated at $70^{\circ} \mathrm{C}$ for 2 at least hours. The elastomeric polymer print was detached, and 2 reservoirs were punched for each chamber. The polymer print and a glass cover slip were cleaned with isopropanol, dried, and treated for 3 minutes in an air plasma generator ( $98 \%$ power, $0.6 \mathrm{mBar}$, Diener Electronic, Ebhausen, Germany) and bonded together. The day before neuronal seeding, chips were UV-sterilized for $20 \mathrm{~min}$, then coated with a solution of poly-D-lysine (10 $\mu \mathrm{g} \cdot \mathrm{ml}^{-1}$ Sigma \#P7280, St. Louis, MO, USA), incubated overnight $\left(37^{\circ} \mathrm{C}, 5 \% \mathrm{CO}_{2}\right)$, and rinsed 3 times with Dulbecco's phosphate buffer saline (D-PBS) (Thermo Fisher Scientific, Invitrogen \#14190169, Waltham, MA, USA). Then, 4 hours before cell seeding, chips were treated with a solution of Laminine ( $5 \mu \mathrm{g} / \mathrm{mL}$ : Sigma) in D-PBS. Brainies ${ }^{\text {TM }}$ MBBT5 is a chip with a design containing 4 neuronal diodes. One neuronal diode includes 2 rectangular culture chambers (volume $\sim 1 \mu \mathrm{L}$ ) each connected to 2 reservoirs and separated by a series of $500 \mu \mathrm{m}$-long asymmetrical micro-channels ( $3 \mu \mathrm{m}$ high, tapering from $15 \mu \mathrm{m}$ to $3 \mu \mathrm{m}$ ). Brainies ${ }^{\mathrm{TM}}$ MBBT4 is a chip containing 8 rectangular culture chambers (volume $\sim 1 \mu \mathrm{L}$ ) each connected to two reservoirs but devoid of microchannels to connect chambers.

\section{Primary neuron microcultures}

All animals were ethically maintained and used compliance with the European Policy and Ethics. E16 embryos (Swiss mice, Janvier, Le Genest Saint Isle, France) were micro-dissected in Gey's Balanced Salt Solution (GBSS, Sigma (without $\mathrm{CaCl}_{2}$ and $\mathrm{MgCl}_{2}$ ) supplemented with $0,1 \%(w / v)$ glucose (Invitrogen). Structures were digested with papain (20U/mL, Sigma \#76220) in DMEM Glutamax (31966; Invitrogen) for $15 \mathrm{~min}$ at $37^{\circ} \mathrm{C}$. After papain inactivation with $10 \%(\mathrm{v} / \mathrm{v})$ of fetal bovine serum (GE Healthcare, U. K.) structures were mechanically dissociated in DMEM Glutamax containing DNAse-I (100 U/mL, D5025, Sigma). After 10 min centrifugation at $700 \mathrm{~g}$, cortical and hippocampi cells were resuspended in DMEM Glutamax supplemented with $10 \%$ FBS, 1\% streptomycin/penicillin (Life Technologies), N2 supplement 
(17502048; Thermo Fisher Scientific), and B-27 supplement (17504-044, Thermofisher Scientific). For the monoculture model (MBBT4 devices), $20.10^{3}$ hippocampal neurons were seeded in each chamber. For the compartmentalized coculture model (neuronal diode in MBBT5 devices), $40.10^{3}$ cortical cell and $15.10^{3}$ hippocampal cells were seeded in each input chambers and output chamber, respectively. The culture medium was renewed every 5 days. Microfluidic chips were placed in Petri dishes containing 0,1\% EDTA (Sigma) and incubated at $37^{\circ} \mathrm{C}$ in $5 \% \mathrm{CO}_{2}$ atmosphere. In the neuronal diodes, cortical axons entered the microchannels and reached the hippocampi chamber in around 4-5 days. In both the monoculture and coculture systems, cells were cultured for 3 weeks to allow high dendrites and synapses density and intense electrical firing. GFAP staining, consistently showed that astrocytes represented less than $5 \%$ of the cultures.

\section{$\beta$-Amyloid and pharmacological treatments in microculture models}

Cells were treated with caspase inhibitors and/or $A \beta_{1-42}$ at 20 days in vitro (DIV). For the hippocampal monocultures, the culture medium was removed and replaced by fresh medium optionally containing $10 \mathrm{nM} \mathrm{A} \beta_{1-42}$ oligomers or monomers, with or without caspase inhibitors. After 6h, cells were fixed, permeabilized, and subjected to immunolabelling. For corticohippocampal compartmentalized cocultures, the medium of the input chamber (cortical) was replaced by fresh medium optionally containing $100 \mathrm{nM} A \beta_{1-42}$ oligomers or monomers, whereas the medium of the output (hippocampal) chamber was replaced by fresh medium optionally containing, or not, caspases inhibitors. To ensure fluidic isolation between input and output chamber of each neuronal diodes, a differential hydrostatic pressure between chambers was maintained. After $6 \mathrm{~h}$, cells were fixed, permeabilized, and hippocampal neurons (output compartment) were subjected to immunolabelling.

Immunofluorescence, detection, and image acquisition

Immunostaining was performed directly in microfluidic chambers as described [38]. Briefly, neurons were fixed for $20 \mathrm{~min}$ at RT in D-PBS containing $4 \%(\mathrm{w} / \mathrm{v})$ paraformaldehyde (PFA) (Euromedex \#15714-S, Souffelweyersheim, France) and 4\% (w/v) sucrose (Sigma \#S0389). Cells were then washed once with D-PBS for $10 \mathrm{~min}$ and permeabilized for 30 minutes with DPBS containing $0,2 \%(\mathrm{v} / \mathrm{v})$ Triton X-100 (Sigma) and $1 \%(\mathrm{w} / \mathrm{v})$ BSA (Sigma). Solutions of primary antibodies, diluted in PBS, were incubated for $2 \mathrm{~h}$ at RT. Cultures were rinsed 2 times for 5 min with PBS and further incubated with the corresponding secondary antibodies for $2 \mathrm{~h}$ at room temperature. For characterization of neuronal culture quality, the following conjugated antibodies were used: anti-ßIII tubulin-Alexa Fluor 488 (1:500, AB15708A4; Millipore), anti- 
microtubule-associated protein 2 (MAP2) Alexa 555 (1:500, MAB3418A5; Millipore), antimicrotubule-associated protein 2 (MAP2) Alexa Fluor 647 (1:500, NB120-11267AF647; Millipore). Cell nuclei were stained by using Hoescht $33342(2 \mu \mathrm{g} / \mathrm{mL}$, Sigma). For synapse loss studies, dendritic spine actin-F was labelled with Phalloidin Alexa Fluor 555 (1:100, A34055; Thermo Fisher Scientific) and the following antibodies were used anti-Bassoon (1:400, SAP7F407; mouse monoclonal; Enzo Life) and anti $\alpha$-synuclein (1:500, D37A6; rabbit polyclonal; Cell Signaling). Species-specific secondary antibodies coupled to Alexa 488 and 350 (1:500; Invitrogen) were used. Images were acquired using an Axio-observer Z1 microscope (Zeiss, Wetzlar, Germany) fitted with a cooled CCD camera (CoolsnapHQ2, Ropert Scientific, Trenton, NJ, USA). During acquisition, the microscope was controlled with MetaMorph $®$ Microscopy Automation \& Image Analysis Software. Images were analyzed using ImageJ software (NIH, Bethesda, MD, USA).

\section{Quantification of Synaptic Disconnection}

Synaptic disconnection was assessed as described [39] with slight modifications. Briefly, in hippocampal monocultures, synaptic disconnection was assessed through fluorescence microscopy by counting phalloidin clusters affixed to MAP2 and Bassoon. In corticohippocampal compartmentalized cocultures, synaptic disconnection was assessed by counting $\alpha$-Synuclein presynaptic clusters affixed to MAP2 positive hippocampal dendrites. All images were obtained using the same acquisition parameters. The images were similarly processed with ImageJ software before being used for quantification: the brightness/contrast of all control images was optimized manually to eliminate the background and to maximize the signal. The means of the minimum and maximum intensities were then calculated in the control condition and these settings were applied to all images. The brightness / contrast of all images was optimized manually to eliminate the background and to maximize the intensity of the signal. a-synuclein/ MAP2 and Phalloidin/MAP2/Bassoon merges were then used for quantification. The number of spines was determined by counting individual clusters along 10 dendritic region (100 um length each) in three independent experiments for every epitope. Only synapses detected on or near the neurites were included for analysis. The resulting synapse counts were then exported to Excel for further analysis. Reported values are means for at least three independent experiments, each performed in triplicate.

\section{Transfections and Immunoblot analysis}

To test SREBP processing, HEK 293 cells were plated at a density of $3 \times 10^{6}$ per well of 10 $\mathrm{cm}$ plates. The next day, $3 \mu \mathrm{g}$ of indicated cDNAs were transfected using lipofectamine 3000 
(Thermo Fisher Scientific, MA) according to manufacturer's instruction. Whole cell lysates (WCL) were prepared in lysate buffer $(150 \mathrm{mM}$ Tris- $\mathrm{HCl}, \mathrm{pH} 7.4,10 \%$ sodium-deoxycholate, $100 \mathrm{mM} \mathrm{NaCl}, 100 \mathrm{mM}$ EDTA, $100 \mathrm{mM}$ PMSF, $200 \mathrm{mM} \mathrm{NaF}, 100 \mathrm{mM} \mathrm{Na}_{3} \mathrm{VO}_{4}$, and a mixture of protease inhibitors. Equal amounts of WCL were subjected to immunoblot (WB) analysis with anti-V5 monoclonal antibody (Cell Signaling Technology; Cat\#13202) [12].

\section{NMR experiments}

Nuclear Magnetic Resonance (NMR) experiments were carried out on a $600 \mathrm{MHz}$ spectrometer equipped with a cryoprobe. LJ3a and LJ3b samples were solubilized in $100 \%$ deuterated DMSO and ${ }^{1} \mathrm{H}$ NMR experiments (1D ${ }^{1} \mathrm{H}, 2 \mathrm{D}$ TOCSY [Suppl Ref 1], 2D COSY) [Suppl Ref 2], [Suppl Ref 3], 2D NOESY [Suppl Ref 4], [Suppl Ref 5]) (Supplementary material, Figure S1A and Figure S2A), ${ }^{13} \mathrm{C}$ experiments in natural abundance $\left(1 \mathrm{D}{ }^{13} \mathrm{C}, 2 \mathrm{D}{ }^{1} \mathrm{H}-{ }^{13} \mathrm{C} \mathrm{HSQC}\right.$ [Suppl Ref 6], 2D ${ }^{1} \mathrm{H}-{ }^{13} \mathrm{C} \mathrm{HMBC}$ ) [Suppl Ref 7]) (data not shown) and ${ }^{15} \mathrm{~N}$ experiments in natural abundance ${ }^{1} \mathrm{H}-{ }^{15} \mathrm{~N}$ SOFAST-HMQC [Suppl Ref 8] (Fig. 6a,b) were recorded. The ${ }^{1} \mathrm{H}-{ }^{15} \mathrm{~N}$ SOFAST-HMQC [Suppl Ref 8] experiments in natural abundance allow to register a twodimensional heteronuclear correlation spectrum of the pseudo-peptide and make it possible to correlate the chemical shift of one amide proton on the abscissa axis with the chemical shift of the nitrogen which carries it on the ordinate axis for each of the amino acids (Fig. 6a, b). The ${ }^{1} \mathrm{H}$ TOCSY [Suppl Ref 1] experiment makes it possible to identify all the protons belonging to the same spin system thanks to the magnetization transfer through the bonds. Then, the succession and the order of the different residues in the pseudo-peptide is identified thanks to the NOESY [Suppl Ref 4], [Suppl Ref 5] experiment which will make it possible to connect the different residues thanks to a transfer of magnetization through space [Suppl. Fig. S1A, S2A].

\section{Theoretical model of the 3D structures}

The theoretical 3D structure of each LJ3 isomers (1R, 2R), (1S, 2R), (1R, 2S) and (1S, 2S) was built and a combination of steepest descent and conjugate gradient methods was used to minimize these structures using UCSF Chimera software 1.12 [Suppl Ref 9]. The distances between protons specific to one or the other isomer were measured on the resulting structures and were compared to the volumes of the NOEs measured on the NOESY spectra of each isomer and to the corresponding NOEs derived distances [Suppl. Methods] [Suppl. Fig. S1, S2]. 
Data are represented as mean \pm SEM or \pm SD as indicated. Differences in mean values were analyzed by Student t-test or one-way ANOVA (for more than 2 groups) and post-hoc Tukey test. For all analysis ${ }^{* * *} p<0.0001 ;{ }^{* * *} p<0.001 ;{ }^{* *} p<0.01 ;{ }^{*} p<0.1$. Statistical analyses were performed using GraphPad Prism 9 software. 


\section{Results}

\section{$S_{2}$ pocket of the Caspase-2 active site as a determinant for inhibitor selectivity}

The S2 subsite of Casp2 forms a long groove that runs perpendicular to the active site cleft, whereas the Casp3 S2 subsite is lipophilic and forms a round, bowl-like shape that can preferentially bind shorter hydrophobic resides. ${ }^{32}$ Targeting the Casp2 S2 subsite with either longer R-groups or bulkier amino acids (that would likely sterically clash with Tyr204 in Casp3) could be an effective strategy in selectively targeting Casp-2. As a starting point, we have evaluated, on both recombinant Casp2 and Casp3, the $\mathrm{IC}_{50}$ and $\mathrm{K}_{\mathrm{i}}$ values of a series of pentapeptide-based reversible Casp-2 inhibitors including the canonic Ac-VDVAD-CHO, and derivatives modified at the P2 position. The four P2-modified pentapeptides aldehydes (Fig.1a), namely c33, k33, q33, and h33, where chosen from a medicinal chemistry series reported by Maillard et al, because these authors showed $\mathrm{IC}_{50}$ values indicating improved selectivity toward Casp2 (reduced Casp3 inhibition) as compared to Ac-VDVAD-CHO [32]. We extended the characterization of these inhibitors and found that $\mathrm{q} 33$ and $\mathrm{h} 33$ present $\mathrm{K}_{\mathrm{i}}$ ratio (Casp3/Casp2) of 94,5 and 597, respectively (Fig.1b-f). When compared to the Ac-VDVAD$\mathrm{CHO} \mathrm{K}_{\mathrm{i}}$ ratio (Casp3/Casp2), this represents 126 times and 796 times improvement of selectivity for q33 and h33, respectively.

As caspase-2 is reportedly required for cell death induced by cytoskeletal disruption [40], we used the depolymerizing agent vincristine as a cell killing model to evaluate the cytoprotective effect of q33 and h33. Vincristine killed HeLa cells at nanomolar concentrations (Fig. 2a, b), and dying cells showed typical nuclear apoptotic morphology (Fig.2c; Hoechst 33342 , blue). In this model, cell death is strictly Caspase-dependent, as $30 \mu \mathrm{M}$ of the standard broad-spectrum caspase inhibitors z-VAD(Ome)-fmk and Q-VD-OPh, but not its control Q-VEOPh, inhibited more than $80 \%$ and $90 \%$ of cell death, respectively (Fig.2d). This was further confirmed with $10 \mu \mathrm{M}$ of Emricasan, a highly potent pan-caspase inhibitor, which abolished 95\% of Vincristin-mediated cell death (Fig.2d). Furthermore, the reversible Casp2 inhibitors q33 and h33 showed cytoprotective effect against vincristine-induced killing (Fig.2e). However, 
the relation dose-effect was not significant, possibly due to the kinetics characteristics of the Vincristin killing and to the reversible properties of $h 33$ and q33.

\section{Design and enzyme kinetics of Casp2-selective irreversible peptidomimetics}

Consequently, we reasoned that a potent and selective Caspase-2 inhibitor should combine the Caspase-2 selectivity of q33 or h33 with the bioavailability, irreversible inhibition, and efficiency of the previously developed group-II caspase inhibitor Q-V(Ome)DVA(Ome)DOPh (also known as TRP-601), or its highly active metabolite Q-VDVAD-OPh (also known as $\triangle 2 \mathrm{Me}-\mathrm{TRP} 601$ ) [31]. We consequently designed LJ2 and LJ3, two peptidomimetics of general structure Q-Val-Asp-Val-X-Asp-OPh (Q-VDVXD-OPh) where $Q$ is a quinaldoyl, OPh is a 2,6difluorophenyloxymethylketone, and $\mathrm{X}$ is either a 6-methyl-1,2,3,4-tetrahydroisoquinoline-1carbonyl (within LJ2) or a 3-neopentyl-Proline (within LJ3) (Fig. 3).

The inhibitory potency of the newly synthetized LJ2 compound toward recombinant human Casp2 was evaluated. LJ2, as $\triangle 2 \mathrm{Me}$-TRP601, behaved as a dose- and time-dependent inhibitor of Casp2 (Fig4a-d; LJ2/Casp2 IC $50=0.37 \pm 0,01 \mathrm{nM} ; \Delta 2 \mathrm{Me}-\mathrm{TRP} 601 / \operatorname{Casp2} \mathrm{IC}_{50}=$ $0.53 \pm 0,02 \mathrm{nM} ; \mathrm{n}=5) . \Delta 2 \mathrm{Me}-\mathrm{TRP} 601$ confirmed to be a powerful inhibitor of Casp3 $(\Delta 2 \mathrm{Me}-$ TRP601/Casp3 $I_{50}=0.31 \pm 0,01 \mathrm{nM} ; \mathrm{n}=5$ ) [31], whereas LJ2 had a 350 times lower effect on Casp3 as compared to Casp2 (LJ2/Casp3 IC 50 of $140.3 \pm 5 n M ; n=5)$ (Fig.4e-h). Then, the kinetic parameters $\mathrm{k}_{3} / \mathrm{K}_{\mathrm{i}}, \mathrm{k}_{3}$, and $\mathrm{K}_{\mathrm{i}}$, were determined (Fig.4i). LJ2 and $\Delta 2 \mathrm{Me}$-TRP601 are both excellent inactivator of Casp2 showing $\mathrm{k}_{3} / \mathrm{K}_{\mathrm{i}}$, ratio of $\sim 1322875 \mathrm{M}^{-1} \mathrm{~s}^{-1}$ and $\sim 1586020 \mathrm{M}^{-1} \mathrm{~s}^{-1}$, respectively. LJ2 was still able to inactivate Casp3 but 25 times less than Casp2 (LJ2/Casp3 $\mathrm{k}_{3} / \mathrm{K}_{\mathrm{i}}$, ratio $\left.=51992 \mathrm{M}^{-1} \mathrm{~s}^{-1} ; \mathrm{n}=3\right)$.

\section{LJ2 inhibits cell death in human cell lines subjected to microtubule destabilization or histone deacetylase inhibition}

We then evaluated the cytoprotective potential of LJ2 in cell death assays. When added to cell lines or primary neurons in culture, LJ2 was devoid of any toxicity at least up to $100 \mu \mathrm{M}$ (not shown). LJ2 significantly prevented Vincristin-induced cell death in a dose-dependent manner (Fig5a). A similar cytoprotective pattern was found with the group-Il caspase inhibitor $\Delta 2 \mathrm{Me}$ - 
TRP601, whereas the Caspase-8 inhibitor Q-LETD-OPh (also known as TRP801) had no effect on Vincristin-induced cell killing. We also evaluated the effect of LJ2 against cell death induced by the deacetylase inhibitor Panobistat (LBH589) in lymphoid human T cells lines. Reportedly LBH589 induces caspase-2 dependent apoptotic cell death in lymphoid cell lines [41]. Accordingly, LJ2 showed a dose-dependent inhibition of cell death (Fig. 5b). In this model the pan Caspase inhibitor Q-VD-OPh, strongly inhibited cell death, whereas inhibition of the inflammatory caspases (Casp1, -4, -5) with Belnacasan (also known as VX-765) did not affect cell death (Fig. 5b,c).

\section{Optimization of highly effective and potent Casp2-selective inhibitors}

Synthesis of LJ2 leads to racemization in P2 and P1. Consequently, the compound LJ2 is a mixture of 4 diastereoisomers. Additional purification steps allowed to separate two group of diastereoisomers, LJ2a and LJ2b, harboring stereoselectivity in P2. We then decided to synthetize LJ3 and adopted a similar purification approach to separate the P2-stereoselective diastereoisomers LJ3a and LJ3b.

Then, we have determined the kinetic parameters $k_{3} / K_{i}, k_{3}$, and $K_{i}$, for LJ2a, LJ2b, LJ3a, and LJ3b on human Casp2 and Casp3 (Table 1). LJ2a is a highly potent Casp2 inactivator showing a subnanomolar $\mathrm{K}_{\mathrm{i}}$ for Casp2 and a $\mathrm{k}_{3} / \mathrm{K}_{\mathrm{i}}$ ratio of $\sim 5500000 \mathrm{M}^{-1} \mathrm{~s}^{-1}$ (i.e. $400 \%$ improvement as compared to LJ2). LJ2a also inactivates Casp3 but $\sim 50$ times less than Casp2 (LJ2aCasp3 $\left.\mathrm{k}_{3} / \mathrm{K}_{\mathrm{i}}=113425 \mathrm{M}^{-1} \mathrm{~s}^{-1}\right)$. Spatial orientation of the 6-methyl-1,2,3,4-tetrahydroisoquinoline-1carbonyl residue (P2 position) appeared crucial for Casp2 inactivation as the $k_{3} / K_{i}$ ratio of $L J 2 b$ against Casp2 is 765 times lower than the one of LJ2a.

$\mathrm{LJ} 3 \mathrm{a}$ is also an excellent inactivator of Casp2 showing a $2.8 \mathrm{nM} \mathrm{K} \mathrm{K}_{\mathrm{i}}$ and $\mathrm{k}_{3} / \mathrm{K}_{\mathrm{i}}$ ratio of $\sim 1709$ $000 \mathrm{M}^{-1} \mathrm{~s}^{-1}$ vis-a-vis Casp2. Comparatively, LJ3a has a low inactivation rate on Casp3 (946 times less than for Casp2) (LJ3aCasp3 $\left.\mathrm{k}_{3} / \mathrm{K}_{\mathrm{i}}=1807 \mathrm{M}^{-1} \mathrm{~s}^{-1}\right)$. Spatial orientation of the 3neopentyl-Proline residue (P2 position) appeared crucial for Casp2 inactivation as the $k_{3} / K_{i}$ ratio of LJ3b against Casp2 was more than 2000 times lower than the one of LJ3a. 
Additional enzyme kinetics experiments with human recombinant Caspase-1, Caspase-6, Cathepsin-B, Cathepsin-L, Cathepsin-D, Thrombin, Plasmin, Trypsin, Kallikrein-1, -6, and -8 indicates that LJ2a and LJ3a have very limited or no effect on these enzymes at least when used at concentrations up to $10 \mu \mathrm{M}$. The only observed effect was a weak Casp-6 inhibition by LJ2a (LJ2a Casp6 $\left.\mathrm{K}_{3} / \mathrm{K}_{\mathrm{i}}=14.2 \mathrm{M}^{-1} \mathrm{~s}^{-1}\right)$ but not by LJ3a. Hence, LJ2a is the most potent Caspase2 inhibitor ever reported, and it is a mild inhibitor of Caspase-3. LJ3a is both a highly potent and genuinely selective Casp2 inhibitor.

\section{Structural Characterization of LJ3a and LJ3b.}

Consequently, we decided to further characterize the LJ3a and LJ3b compounds by NMR and molecular modeling. ${ }^{1} \mathrm{H}-{ }^{15} \mathrm{~N}$ SOFAST-HMQC experiments in natural abundance allowed to observe each peak corresponding to one amino acid at positions P5 (Val 5), P4 (Asp 4), P3 (Val 3) and P1 (Asp-OPh). No signal can be observed for the position P2 (3-neopentyl proline) since the nitrogen of the proline does not carry a proton. The ${ }^{1} \mathrm{H}-{ }^{15} \mathrm{~N}$ SOFAST-HMQC experiments in natural abundance performed on the LJ3a and LJ3b samples showed a doubling of some resonances demonstrating that they did not contain a single isomer but a mixture of 2 different isomers (Fig. 6a,b). These results were confirmed by $1 \mathrm{H}$ NMR experiments performed on these samples (Suppl. Fig. S1A, S2A). The resonances corresponding to the amide group $\mathrm{N} 6 \mathrm{H} 36$ in position $\mathrm{P} 1$ (ASP 1) are split in each ${ }^{1} \mathrm{H}-{ }^{15} \mathrm{~N}$ SOFAST-HMQC experiment in natural abundance performed on the samples LJ3a and LJ3b. The resonances of the amide group N2H7 corresponding to position P5 (VAL 5) and amide group N3H16 at position P4 (ASP 4) are unique in the 2 samples confirming the absolute configuration $S$ is unchanged for the $2 \alpha$-carbons $\mathrm{C} 11$ and $\mathrm{C} 16$ at position P5 and P4 respectively (Fig. 6a,b). The two peaks $\mathrm{N} 6 \mathrm{H} 36$ corresponding to the two isomers at position P1 appeared to be in a 50/50 ratio when measuring the volume of the correlation peaks for each sample. This indicated a racemization of the $\alpha$-carbon $\mathrm{C} 30$ at the position P1. In both samples, LJ3a and LJ3b, the resonances of the amide group N4H21 at position P3 (Val 3) showed the presence of 2 signals. However, the absolute configuration $\mathrm{S}$ of this carbon should 
remain unchanged due to the solid phase synthesis mode used and it cannot be ruled out that the electronic environment of the $\mathrm{H} 21$ is changed due to the racemization of the position $\mathrm{P} 1$ (ASP 1), resulting in the doubling of the signals of the amide group. The N5 of proline 2 in position P2 does not carry a proton and is therefore not observable on the ${ }^{1} \mathrm{H}-{ }^{15} \mathrm{~N}$ SOFASTHMQC experiments. Nevertheless, the $\mathrm{H} \alpha(\mathrm{H} 32)$ of the 3-neopentyl proline in position P2 shows two distinct resonances showing that it undergoes an effect due to the presence of the two isomers in position P1. Thus, the $\alpha$-carbon at the position $\mathrm{P} 1$ is racemic and position P2 is optically pure. Then, the full assignment of the isomers and exact structures of LJ3a (Fig. 6c-e) and LJ3b (Fig. 6f-h) were established using ${ }^{1} \mathrm{H}$ NMR experiments and comparison of spectra with theoretical models (Suppl. Fig S1, S2, Suppl Table 1, 2).

\section{LJ2a and LJ3a protect primary neurons against $\beta$-amyloid-induced synapse loss}

Caspase- 2 is critical for the effects of $A \beta$ on dendritic spines in cultured neurons and has a critical role in mediating the synaptic changes and memory alteration induced by $A \beta$ in human amyloid precursor protein transgenic mice, suggesting that Caspase-2 is a potential target for Alzheimer's disease therapy [17]. We cultured hippocampal neurons and exposed them to low (subapoptotic) concentrations of oligomeric $A \beta_{1-42}(\mathrm{nM}$ range) with and without Caspase-2 inhibitors and examined the effects on dendritic spine density (Fig.7). This resulted in a 50\% decrease in spine density after $6 \mathrm{~h}$ of exposure. These effects were not seen in neurons exposed to monomeric $A \beta_{1-42}$. When submicromolar concentration of LJ2a were added, there was a full blockade of the effect of oligomeric $A \beta$ on spine density (Fig $7 b$ ). LJ3a pretreatment at $0.1 \mu \mathrm{M}, 1 \mu \mathrm{M}$, and $10 \mu \mathrm{M}$ prevented dendritic spine loss induced by oligomeric $A \beta$ at $59.63 \%$, $89.29 \%$, and $97.5 \%$ respectively (Fig $7 \mathrm{c}$ ).

\section{LJ2a and LJ3a abolish Casp2-dependent SREBP2 activation.}

Previously, it was found that Casp2 activates SREBP1 and 2, the master regulators of lipogenesis and cholesterol biosynthesis, through the cleavage-mediated activation of S1P [12]. Casp2 inhibition reduces hepatic steatosis and steatohepatitis, inflammation, and liver 
damage, as well as it prevents cholesterol accumulation and hyperlipidemia, suggesting that Casp2 is an interesting target for the prevention or treatment of $\mathrm{NASH}$ [12]. To evaluate Casp2 inhibitor effects on SREBP activation, we added the inhibitors to HEK293 cells transfected with Casp2, S1P, and SREBP2 (Fig. 8a, b). Under these conditions, Casp2 cleaves and activates S1P which then cleaves and activates SREBP2 resulting in nuclear translocation of the SREBP2 transcriptional activation domain [12] (Fig. 8b, Lane 2). Strikingly, addition of LJ2a or LJ3a completely abolished Casp2- and S1P-dependent SREBP2 activation (Fig. 8b, Lane 4, 6) while TRP601 led to partial inhibition (Lane 8).

\section{Discussion}

Caspases are implicated in the pathogenesis of numerous diseases. Hundreds of caspasespecific inhibitors have been designed, few have progressed to clinical trials, and to date no one has reached market authorization. This is due, at least in part, to the use of non-selective approaches to caspase inhibition which inhibit the whole family rather than the key family member responsible for pathology. Designing highly selective and druggable reagents to distinguish among closely related enzymes of the caspase family remains a major challenge. This difficulty is exacerbated for the design of active-site-directed inhibitor of Casp2 due to high similarity between Casp3 and Casp2 active sites.

We have designed and evaluated a series of peptidomimetics inspired from the pentapeptide Val-Asp-Val-Ala-Asp (VDVAD) and included N-terminal quinaldoyl group, potent irreversible C-terminal warhead (proven to be safe in human), and chosen non-natural bulky structures in P2 to generate new compounds harboring higher biodisponibility, improved efficiency, and enhanced selectivity toward Caspase-2. ${ }^{31-33}$ Our results define a series of highly potent Casp2 inhibitors having the general structure: Quinaldoyl-Val ${ }^{\mathrm{P} 5}-\mathrm{Asp}^{\mathrm{P} 4}-\mathrm{Val}^{\mathrm{P} 3}-\mathrm{X}^{\mathrm{P} 2}-\mathrm{Asp}^{\mathrm{P} 1}$ fluorophenoxy-methyl-ketone (Q-VDVXD-OPh) with $X^{P 2}$ being either 6-methyl-tetrahydroisoquinoline (LJ2 and LJ2a) or a 3-(S)-neopentyl proline (LJ3a). LJ2 has high inactivation rate 
on Casp2 $\left(\mathrm{k}_{3} / \mathrm{K}_{\mathrm{i}} \sim 1300000 \mathrm{M}^{-1} \mathrm{~s}^{-1}\right)$ and shows selectivity ( 25 times higher as compared to Casp3). In cell lines, LJ2 dose-dependently inhibits cell death induced by microtubule destabilization or hydroxamic acid-based deacetylase inhibition, two Casp2-dependent cell deaths paradigms. LJ2a (further purified from LJ2), is the most active compound. It has a subnanomolar $\mathrm{K}_{\mathrm{i}}$ for Casp2, a very high inactivation rate on Casp2 $\left(\mathrm{k}_{3} / \mathrm{K}_{\mathrm{i}} \sim 5500000 \mathrm{M}^{-1} \mathrm{~s}^{-1}\right)$ and show good selectivity ( $\sim 50$ times higher as compared to Casp3). The most selective compound, LJ3a, has a high inactivation rate on Casp2 $\left(\mathrm{k}_{3} / \mathrm{K}_{\mathrm{i}} \sim 1700000 \mathrm{M}^{-1} \mathrm{~s}^{-1}\right)$ and high selectivity ( 1000 times higher as compared to Casp3). Enzyme kinetics show that LJ3b isomer has very low activity on Casp2 $\left(\mathrm{k}_{3} / \mathrm{K}_{\mathrm{i}} \sim 800 \mathrm{M}^{-1} \mathrm{~s}^{-1}\right)$. Structural analysis of LJ3a and LJ3b shows that precise spatial configuration R/S of the $\alpha$-carbon in P2 determines inhibitor efficacy. Indeed, NMR spectra analysis and molecular modeling show that the position P2 (3-neopentyl proline) is optically pure in LJ3a whereas the $\alpha$-carbon in P1 is racemic. LJ3a contains the two isomers $\left(P 1_{R}, P 2_{R}\right)$ and $\left(P 1_{S}, P 2_{R}\right)$ while sample $L J 3 b$ contains the two isomers $\left(P 1_{R}, P 2_{s}\right)$ and $\left(\mathrm{P} 1_{\mathrm{s}}, \mathrm{P} 2 \mathrm{~s}\right)$. Hence, the unexpected conclusion is that the S-configuration of the $\alpha$-carbon in P2 (LJ3b) is inactive against Casp2, whereas the R-configuration of the $\alpha$-carbon in P2 (LJ3a) is active.

Casp2 is implicated in several diseases including optic nerve injuries, neonatal brain damage, age-related neurodegeneration, and metabolic diseases. To investigate the effect of LJ2a and LJ3a in pathological conditions, we selected two diseases, AD and NASH, because they are both devastating diseases with a huge world-wide societal impact and so far no drug have shown disease-modifying efficacy against either of them $[42,43]$.

Casp2 is a potential therapeutic target in $\operatorname{AD}[17,18]$. Indeed, experiments with primary hippocampal neurons and Casp2-deficient mice implicate Casp2 as key driver of synaptic dysfunction and cognitive decline in AD [17]. Casp2 is present both in neuron cell bodies and dendritic spines and acts as a mediator of $\beta$-amyloid protein (A $\beta$ ) synaptotoxicity. Consequently, one can expect that selective Casp2 inhibitors would inhibit A $\beta$-induced synapse loss. The present study shows that, in primary hippocampal neurons, submicromolar concentrations of LJ2a and LJ3a block synapse loss induced by A 342 oligomers. The 
preclinical development of the (less selective) parent compound, TRP601, was previously reported [31]. It was found to be non-toxic in regulatory rodent and non-rodent studies, to inhibit of Casp2 in the brain, and to confer neuroprotection after ip and iv administration [31]. One can expect that LJ2a and LJ3a may have such favorable safety and PK properties. Further studies in human cells and animal models of $A D$ are ongoing to investigate the potential of LJ2a and LJ3a for the treatment of AD.

The first in class dipeptide derivative irreversible pan-caspase inhibitor, Emricasan, has been thoroughly investigated in several clinical studies for a variety of liver diseases. This drug candidate, recently failed to demonstrate efficacy in large clinical phase 3 studies for the treatment of NASH $[44,45]$. Those studies however, provided important information that contradicted broadly held opinion, showing that chronic administration of an irreversible broadspectrum Caspase inhibitor is not toxic nor carcinogenic in humans (Clinical Trials.gov \#NCT02686762 and \#NCT02960204) [44, 45]. This paves the way for the development of more selective drugs directed against individual Caspases. Other recent studies in cellular and animal models, have highlighted the importance of Casp2, in NASH progression [12]. Indeed, Casp2 inhibition may lead to reduced lipoapoptosis and steatohepatitis, and block the production of fibrogenic Hedgehog ligands, which aggravate NASH progression [11, 46]. More recently, it was suggested that Casp2 activation is a critical mediator of the transition from benign non-alcoholic fatty liver disease (NAFLD) to NASH [12]. Casp2 activation was associated with dysregulated SREBP1/2 activation, which is accompanied by lipid and cholesterol accumulation within the liver [14]. Altogether these findings imply that Casp2 inhibition could be a valid therapeutic approach to stop the pathogenic progression that leads to NASH. Considering the failure of Emricasan clinical results, we suggest that successful prevention or treatment of NASH would require the use of a Casp2-specific inhibitor. Our data show that LJ2a and LJ3a inhibit the Casp2 mediated processing of SREBP2, in a cellular model. This suggests that LJ3a and LJ2a should be further investigated and optimized for in vivo activity to determine if selective Casp2 inhibitors could offer an effective approach to the prevention or treatment of fatty liver diseases. 
bioRxiv preprint doi: $h$ ttps://doi.org/10.1101/2021.12.13.472505; this version posted December 15, 2021. The copvright holder for this preprint (which was not certified by peer review) is the author/funder. All rights reserved. No reuse allowed without permission. 


\section{Acknowledgements}

We thank Dr Michel Maillard (CHDI) for advice and kindly providing reversible Caspase-2 inhibitors (q33, h33, k33 and c33). Elodie Bosc was funded by MESNR. We thank Ségolène Prétat and Hugot Cochet for technical assistance. This work was funded by ANR “Neuroscreen: 2011-RPIB-008-001" 2012-16 (to BB), SATT IDF Maturation grant (to EJ), iXLife-iXCore-iXBlue Fondation pour la Recherche (to EJ), and NIH grant DK120714 (to MK).

\section{Declaration of interests}

E.J. is inventor of a patent titled "Novel derivatives and their use as selective inhibitors of Caspase-2" (WO/2017/162674). E.J. and E.B. are inventors of a patent titled "Novel compounds and their use as selective inhibitors of Caspase-2" WO/2019/068538. MK hold a patent on mouse models for the treatment of $\mathrm{NASH}$, is a founder of Elgia Pharmaceuticals and had received research support from Jansen and Gossamer Bio. 


\section{References}

1. Rawlings ND \& Salvesen G (eds). Handbook of Proteolytic Enzymes. $3^{\text {rd }}$ edn. Elsevier, London 2013), Vol.2 (chap. 505-513): 2237-85.

2. Van Opdenbosch N, Lamkanfi M. Caspases in Cell Death, Inflammation, and Disease. Immunity 50(6), 1352-64 (2019).

3. Shalini S, Dorstyn L, Dawar S, Kumar S. Old, new and emerging functions of caspases. Cell Death Differ 22, 526-39 (2015).

4. Linton SD. Caspase inhibitors: a pharmaceutical industry perspective. Curr Top Med Chem 5(16), 1697-717 (2005).

5. Dhani S, Zhao Y, Zhivotovsky B. A long way to go: caspase inhibitors in clinical use. Cell Death Dis 12(10), 949 (2021).

6. Pop C, Salvesen GS. Human caspases: activation, specificity, and regulation. $J$ Biol Chem 284(33), 21777-81 (2009).

7. Miles MA, Kitevska-llioski T, Hawkins CJ. Old and Novel Functions of Caspase-2. Int Rev Cell Mol Biol 332, 155-212 (2017).

8. Vigneswara V \& Ahmed Z. The Role of Caspase-2 in Regulating Cell Fate. Cells 9(5), 1259 (2020).

9. Bergeron L, Perez GI, Macdonald G, Shi L, Sun Y, Jurisicova A, et al. Defects in regulation of apoptosis in caspase-2-deficient mice. Genes Dev 12(9), 1304-14 (1998).

10. Bouchier-Hayes L, Oberst A, McStay GP, Connell S, Tait SW, Dillon CP, et al. Characterization of cytoplasmic caspase-2 activation by induced proximity. Mol Cell 35(6), 830-40 (2009).

11. Machado MV, Michelotti GA, Pereira Tde A, Boursier J, Kruger L, Swiderska-Syn M, et al. Reduced lipoapoptosis, hedgehog pathway activation and fibrosis in caspase-2 deficient mice with non-alcoholic steatohepatitis. Gut 64(7), 1148-57 (2015).

12. Kim JY, Garcia-Carbonell R, Yamachika S, et al., ER Stress Drives Lipogenesis and Steatohepatitis via Caspase-2 Activation of S1P. Cell 175(1), 133-145 (2018).

13. Xu ZX, Tan JW, Xu H, et al., Caspase-2 promotes AMPA receptor internalization and cognitive flexibility via mTORC2-AKT-GSK3ß signaling. Nat Commun 10(1), 3622 (2019).

14. Carlsson Y, Schwendimann L, Vontell R, et al., Genetic inhibition of caspase-2 reduces hypoxicischemic and excitotoxic neonatal brain injury. Ann Neurol 70(5), 781-9 (2011).

15. Ahmed Z, Kalinski H, Berry M, et al., Ocular neuroprotection by siRNA targeting Caspase-2. Cell Death Disease 2, e173 (2011).

16. Troy CM, Rabacchi SA, Friedman WJ, Frappier TF, Brown K, Shelanski ML. Caspase-2 mediates neuronal cell death induced by beta-amyloid. J Neurosci 20(4), 1386-92 (2000).

17. Pozueta J, Lefort R, Ribe EM, Troy CM, Arancio O, Shelanski ML. Caspase-2 is required for dendritic spine and behavioural alterations in J20 APP transgenic mice. Nat Commun 4, 1939 (2013).

18. Zhao X, Kotilinek LA, Smith B, Hlynialuk C, Zahs K, Ramsden M, et al. Caspase-2 cleavage of tau reversibly impairs memory. Nat Med 22(11), 1268-1276 (2016).

19. Poreba M, Szalek A, Kasperkiewicz P, Rut W, Salvesen GS, Drag M. Small Molecule Active Site Directed Tools for Studying Human Caspases. Chem Rev 115(22), 12546-629 (2015).

20. Chauvier D, Ankri S, Charriaut-Marlangue C, Casimir R, Jacotot E. Broad-spectrum caspase inhibitors: from myth to reality? Cell Death Differ 14(2), 387-91 (2007).

21. Wannamaker W, Davies R, Namchuk M, Pollard J, Ford P, Ku G, et al. (S)-1-((S)-2-\{[1-(4amino-3-chloro-phenyl)-methanoyl]-amino\}-3,3-dimethyl-butanoyl)-pyrrolidine-2-carboxylic acid ((2R,3S)-2-ethoxy-5-oxo-tetrahydro-furan-3-yl)-amide (VX-765), an orally available selective interleukin (IL)-converting enzyme/caspase-1 inhibitor, exhibits potent antiinflammatory activities by inhibiting the release of IL-1beta and IL-18. J Pharmacol Exp Ther 321(2), 509-16 (2007).

22. Linton SD, Aja T, Armstrong RA, Bai X, Chen LS, Chen N, et al., First-in-class pan caspase inhibitor developed for the treatment of liver disease. J Med Chem 48(22), 6779-82 (2005). 
23. Kim HR, Tagirasa R, and Yoo E. Covalent Small Molecule Immunomodulators Targeting the Protease Active Site. J. Med. Chem. 2021, 64, 9, 5291-5322.

24. Poreba M, Strózyk A, Salvesen GS, Drag M. Caspase substrates and inhibitors. Cold Spring Harb Perspect Biol 5(8), a008680 (2013).

25. Schweizer A, Briand C, Grutter MG. Crystal structure of caspase-2, apical initiator of the intrinsic apoptotic pathway. J Biol Chem 278(43), 42441-7 (2003).

26. Fang B, Boross PI, Tozser J, Weber IT. Structural and kinetic analysis of caspase-3 reveals role for s5 binding site in substrate recognition. J Mol Biol 360(3), 654-66 (2006).

27. Talanian RV, Quinlan C, Trautz S, Hackett MC, Mankovich JA, Banach D, et al. Substrate specificities of caspase family proteases. J Biol Chem 272, 9677-82 (1997).

28. Thornberry NA, Rano TA, Peterson EP, Rasper DM, Timkey T, Garcia-Calvo M, et al. A combinatorial approach defines specificities of members of the caspase family and Granzyme B. Functional relationships established for key mediators of apoptosis. J Biol Chem 272, 1790711 (1997).

29. Degterev A, Boyce M, Yuan J. A decade of caspases. Oncogene 22, 8543-67 (2003).

30. McStay GP, Salvesen GS, Green DR. Overlapping cleavage motif selectivity of caspases: implications for analysis of apoptotic pathways. Cell Death Differ 15, 322-31 (2008).

31. Chauvier D, Renolleau S, Holifanjaniaina S, Ankri S, Bezault M, Schwendimann L, et al. Targeting Neonatal Ischemic Brain Injury with a Pentapeptide-Based Irreversible Caspase Inhibitor. Cell Death Disease 2(9), e203.

32. Maillard MC, Brookfield FA, Courtney SM, Eustache FM, Gemkow MJ, Handel RK, et al. Exploiting differences in caspase-2 and $-3 \mathrm{~S} 2$ subsites for selectivity: structure-based design, solid-phase synthesis and in vitro activity of novel substrate-based caspase-2 inhibitors. Bioorg Med Chem 19(19), 5833-51 (2011).

33. Bosc E, Anastasie J, Soulami F, Pretat S, Lacin G, Duplus E, et al. Selective caspase-2 inhibition and synapse protection with a new irreversible pentapeptide derivative. Abstract of 26th Conference of the European Cell Death Organization (ECDO 2018). Cell Death Discov 5, 54 ECDO81 (2019).

34. Poreba M, Rut W, Grobortz K, Snipas SJ, Salvesen GS, Drag M. Potent and selective caspase2 inhibitor prevents MDM-2 cleavage in reversine-treated colon cancer cells. Cell Death Diff 26, 2695-2709 (2019).

35. Doucet C, L Pochet, N Thierry, B Pirotte, J Delarge, M Reboud-Ravaux. 6-Substituted 2-oxo$2 \mathrm{H}$-1-benzopyran-3-carboxylic acid as a core structure for specific inhibitors of human leukocyte elastase. J Med Chem 42(20), 4161-71 (1999).

36. Stine WB, Dahlgren KN, Krafft GA, LaDu MJ. In vitro characterization of conditions for amyloidbeta peptide oligomerization and fibrillogenesis. J Biol Chem 278(13), 11612-11622 (2003).

37. Magnifico S, Saias L, Deleglise B, Duplus E, Kilinc D, Miquel MC, et al. NAD+ acts on mitochondrial SirT3 to prevent axonal caspase activation and axonal degeneration. FASEB J 27(12):4712-22 (2013).

38. Deleglise B, Lassus B, Soubeyre V, Alleaume-Butaux A, Hjorth JJ, Vignes M, et al. Synaptoprotective drugs evaluation in reconstructed neuronal network. PLoS One 8(8), e71103 (2013).

39. Deleglise B, Magnifico S, Duplus E, Vaur P, Soubeyre V, Belle M, et al. $\beta$-amyloid induces a dying-back process and remote trans-synaptic alterations in a microfluidic-based reconstructed neuronal network. Acta Neuropathol Commun 2, 145 (2014).

40. Ho LH, Read SH, Dorstyn L, Lambrusco L, Kumar S. Caspase-2 is required for cell death induced by cytoskeletal disruption. Oncogene 27, 3393-3404 (2008).

41. Hasegawa H, Yamada Y, Tsukasaki K, Mori N, Tsuruda K, Sasaki D, et al. LBH589, a deacetylase inhibitor, induces apoptosis in adult T-cell leukemia/lymphoma cells via activation of a novel RAIDD-caspase-2 pathway. Leukemia 25(4), 575-587 (2011).

42. Younossi Z, Anstee QM, Marietti M, Hardy T, Henry L, Eslam M, et al. Global burden of NAFLD and NASH: trends, predictions, risk factors and prevention. Nat Rev Gastroenterol Hepatol 15(1), 11-20 (2018). 
43. Cummings J, Lee G, Zhong K, Fonseca J, Taghva K. Alzheimer's disease drug development pipeline: 2021. Alzheimer's Dement (NY) 7(1), e12179 (2021).

44. Garcia-Tsao G, Bosch J, Kayali Z, Harrison SA, Abdelmalek MF, Lawitz E et al., Randomized Placebo-Controlled Trial of Emricasan in Non-alcoholic Steatohepatitis (NASH) Cirrhosis with Severe Portal Hypertension. J Hepatol 72(5), 885-895 (2020).

45. Harrison SA, Goodman Z, Jabbar A, Vemulapalli R, Younes ZH, Freilich B et al., A randomized, placebo-controlled trial of Emricasan in patients with NASH and F1-F3 fibrosis. $J$ Hepatol 72(5), 816-827 (2020).

46. Machado MV, Michelotti GA, Jewell ML, Pereira TA, Xie G, Premont RT, Diehl AM. Caspase-2 promotes obesity, the metabolic syndrome and nonalcoholic fatty liver disease. Cell Death Dis. 7, e2096 (2016). 


\section{Figure Legends}

\section{Figure 1: Kinetic parameters on Caspase-2 versus Caspase-3 of P2-modified VDVAD pentapeptides derivatives}

a) Structures of reversible Caspase-2/3 inhibitors. Ac-VDVAD-CHO is a non-selective canonical pentapeptide Caspase-2/3 inhibitor, Ac-DEVD-CHO is a canonical tetrapeptide Caspase-3 inhibitor. c33, k33, q33, h33 are VDVAD derivatives where the P2 Alanine residue was replaced by bulky substituent to decrease activity against Caspase-3. b-e) Potent competitive inhibition of Caspase-2 by q33 (b, c) and h33 (d, e). Lineweaver-Burk plots of Casp2 inhibition with q33 (b) and h33 (d) are shown together with the relationship between the slopes of lines in Lineweaver-Burk plot analyses and the concentration of q33 (c) and h33 (e) inhibitors. f). IC50, Ki values and Casp3/Casp2 selectivity ratio of reversible P2-modified VDVAD derivatives. Data points on the graphs represent the mean $\pm S D$, and calculated $K_{\mathrm{i}}$ values represent mean \pm standard error (SE) from 3 independent experiments.

\section{Figure 2: q33 and h33 are protective against the cytocidal effect of Vincristine.}

a) Vincristine induces HeLa cells death. Cells were incubated for $44 \mathrm{~h}$ at $37^{\circ} \mathrm{C}$ with $20 \mathrm{nM}$ Vincristine (VCR), then incubated with propidium iodide at $2 \mu \mathrm{g} / \mathrm{mL}$ for $10 \mathrm{~min}$ and analyzed by flow cytometry to quantify plasma membrane permeabilization. Histograms show fluorescence intensity detected by flow cytometry (one representative experiment) in the presence (VCR) or Absence (Co.) of Vincristine. \% of propidium iodide positive cells are indicated for both conditions. b) Dose-response of Vincristine-induced cell death. HeLa cells were incubated and treated as in (a) with the indicated doses of Vincristine (VCR) and analyzed by flow cytometry. Histogram show the mean $\pm S D$ of 5 independent experiments $\left({ }^{* * *} p\right.$ value $<$ 0.001). c) Vincristine induces apoptotic nuclear morphology in HeLa cells. Representative fluorescence microscopy micrographs of cells treated for $44 \mathrm{~h}$ with $20 \mathrm{nM}$ vincristine (VCR) or not (Co.) and stained with Hoechst 33342. Vincristine induces progressive nuclear changes with first condensed nuclei (arrows) and then apoptotic bodies (dashed arrow). d) Broad- 
spectrum irreversible caspase inhibitors prevent vincristine-induced cell death. HeLa cells were pretreated for $1 \mathrm{hr}$ with the indicated broad-spectrum irreversible caspases inhibitors (z$\operatorname{VAD}(\mathrm{OMe})$-fmk at $30 \mu \mathrm{M}, \mathrm{Q}-\mathrm{VD}-\mathrm{OPh} 30 \mu \mathrm{M}$, Emricasan $10 \mu \mathrm{M}$, or the negative control Q-VEOPh $30 \mu \mathrm{M}$ ), then treated with vincristine as in panel a, and analyzed by flow cytometry. Histograms show the mean +/-SD of 3 independent experiments ( ${ }^{* * *} p$ value $\left.<0.001\right)$. e) Effect of the reversible Caspase- 2 inhibitors q33 and h33 against vincristine-induced cell death. HeLa cells were pretreated for $1 \mathrm{hr}$ with the indicated doses of q33 or $\mathrm{h} 33$, then treated with vincristine as in panel a, and analyzed by flow cytometry. Histograms show the mean +/-SD of 3 independent experiments ( ${ }^{*} p$ value $\left.<0.1\right)$.

\section{Figure 3: structure of Caspase-2 irreversible inhibitors.}

Quinolin-2-carbonyl-VD(OMe)VAD(OMe)- $\mathrm{CH}_{2}-\mathrm{O}\left(2,6 \mathrm{~F}_{2}\right) \mathrm{Ph}$ (referred as TRP601 [31]) and Quinolin-2-carbonyl-VDVAD- $\mathrm{CH}_{2}-\mathrm{O}\left(2,6 \mathrm{~F}_{2}\right) \mathrm{Ph}$ (referred as $\triangle 2 \mathrm{Me}-\mathrm{TRP} 601$ ) are pentapeptide derivatives. Quinolin-2-carbonyl-VDV-(methyl-isoquinolyl)-D- $\mathrm{CH}_{2}-\mathrm{O}\left(2,6 \mathrm{~F}_{2}\right) \mathrm{Ph}$ (referred as LJ2) and Quinolin-2-carbonyl-VDV(3-neopentyl)D- $\mathrm{CH}_{2}-\mathrm{O}\left(2,6 \mathrm{~F}_{2}\right) \mathrm{Ph}$ (referred as LJ3), are pentapeptide-derived peptidomimetics.

\section{Figure 4: kinetic of Caspase-2 vs Capsase-3 inhibitions by TRP601, $\Delta 2 \mathrm{Me-TRP601}$, and}

\section{LJ2.}

a, c. Progress curves of Ac-VDVAD-AMC hydrolysis catalyzed by caspase-2 in the presence of various concentrations of LJ2 (a) and $\Delta 2 \mathrm{Me}$-TRP601 (c), as indicated. The data were obtained under the conditions described in the Materials and methods section $(25 \mu \mathrm{M}$ substrate and $0.2 \mathrm{nM}$ Caspase-2) and analyzed according to Eq. (2-5). b. Values of $k_{\text {obs }}$ obtained from panel "a" plotted versus LJ2 concentrations. d. Values of $k_{\text {obs }}$ obtained from panel "c" plotted versus $\triangle 2 \mathrm{Me}-\mathrm{TRP} 601$ concentrations. e, g. Progress curves of AcDEVD-AMC hydrolysis catalyzed by caspase-3 in the presence of various concentrations of LJ2 (e) and $\triangle 2 \mathrm{Me}$-TRP601 (g), as indicated. The data were obtained under the conditions described in the Materials and methods section (10 $\mu \mathrm{M}$ substrate and $0.1 \mathrm{nM}$ Caspase- 3 ) and 
analyzed according to Eq. (2). f. Values of $k_{\text {obs }}$ obtained from panel "e" plotted versus LJ2 concentrations. h. Values of $k_{\text {obs }}$ obtained from panel "g" plotted versus $\triangle 2 M e-T R P 601$ concentrations. i. The plots in $\mathbf{b}, \mathbf{d}, \mathbf{f}$, and $\mathbf{h}$ were fit according to Eq. (3) to generate $\mathrm{K}_{1}$ and $k_{\text {inact }}\left(\mathrm{k}_{3}\right)$ respective values. Indicated $\mathrm{K}_{\mathrm{i}}$ and $\mathrm{k}_{3}$ value of each inhibitor on Caspase-2 and Caspase-3 are mean values from five independent experiments (SE < 0.07). $\mathrm{K}_{\text {off }}$ rates $\left(\mathrm{K}_{3} / \mathrm{K}_{\mathrm{i}}\right)$ and Casp3/Casp2 selectivity ratio ( $\mathrm{K}_{\text {off }}$ rates Casp3 / $\mathrm{K}_{\text {off }}$ rates Casp2) are also indicated.

Figure 5: LJ2 inhibits cell death induced by microtubule destabilization and hydroxamic acid-based deacetylase (HDAC) inhibition.

a) Effect of the irreversible Caspase-2 inhibitors LJ2 against vincristine-induced cell death. HeLa cells were pretreated for $1 \mathrm{hr}$ with the indicated doses of LJ2, Q-VD-OPh, or Q-LETD$\mathrm{OPh}$, then treated with vincristine (VCR) as in Figure 2, then incubated with propidium iodide at $2 \mu \mathrm{g} / \mathrm{mL}$ for $10 \mathrm{~min}$ and analyzed by flow cytometry. Histogram data are mean $+/-\mathrm{SD}(\mathrm{n}=3$, ${ }^{*} p$ value $\left.<0.01\right)$. b) Effect of Caspases-inhibitors against Panobistat (LBH589)-induced cell death. Molt4 lymphoid human cells where were pretreated for $1 \mathrm{hr}$ with $30 \mu \mathrm{M}$ of LJ2, Q-VDOPh, or Belnacasan (VX-765), then treated for $24 \mathrm{~h}$ with $25 \mathrm{nM}$ of LBH589, then incubated with propidium iodide as in (a) and analyzed by flow cytometry. Histograms data are mean +/-SD $\left(n=4,{ }^{* *} p\right.$ value $\left.<0.001\right)$. c) Dose-response of LJ2-mediated cell death inhibition. Molt4 cells were treated as in (b) with the indicated doses of LJ2 or Q-VD-OPh and analyzed by flow cytometry. Histogram data are mean $+/-S D\left(n=3,{ }^{* *} p\right.$ value $\left.<0.01\right)$.

Figure 6: determination of the absolute configuration of LJ3a and LJ3b by NMR spectroscopy

a. Heteronuclear Multiple Quantum Coherence (HMQC) for LJ3a. Two-dimensional (2D) ${ }^{1} \mathrm{H}-{ }^{15} \mathrm{~N}$ 2D heteronuclear HMQC spectrum of the LJ3a sample showing the correlation between the nitrogen and the proton it carries. The spectrum shows additional peaks due to the racemization of $\mathrm{P} 1$ and corresponding to two different isomers. The assignment has been 
made and the correlations for one isomer are represented in thin letters while the other is in bold. b. HMQC for LJ3b. 2D ${ }^{1} \mathrm{H}-{ }^{15} \mathrm{~N}$ 2D heteronuclear HMQC spectrum of the LJ3b sample showing the correlation between the nitrogen and the proton it carries. The spectrum shows additional peaks due to the racemization of $\mathrm{P} 1$ and corresponding to two different isomers. The assignment has been made and the correlations for one isomer are represented in thin letters while the other is in bold. c. LJ3a molecules of general formula Qco-P5-P4-P3-P2-P1OPh with racemization in $\mathrm{P} 1$ (Asp-OPh) and absolute configuration $\mathrm{R}$ in position P2 (3neopentyl proline). The positions P5 (Val 5), P4 (Asp 4) and P3 (Val 3) have an absolute configuration S. d. Structural 3D model of the $1 \mathrm{~S} 2 \mathrm{R}$ isomer. e. Structural 3D model of the 1R2R isomer. f. LJ3b molecules of general formula Qco-P5-P4-P3-P2-P1-Oph with racemization in $\mathrm{P} 1$ (Asp-OPh) and absolute configuration S in position P2 (3-neopentyl proline). The positions P5 (Val 5), P4 (Asp 4) and P3 (Val 3) have an absolute configuration S. g. Structural 3D model of the $1 \mathrm{~S} 2 \mathrm{~S}$ isomer. $\mathbf{h}$. Structural 3D model of the 1R2S isomer.

Figure 7: LJ2a and LJ3a prevent dendritic spine loss induced by $A \beta$ oligomers in hippocampal primary cultures.

Swiss mice hippocampal neurons (E18) were cultured for 3 weeks in microfluidic chambers (20 000 neurons / chamber). Then neurons were pre-treated, or not, for $1 \mathrm{~h}$ with the indicated concentration of LJ2a or LJ3a, and treated for $6 \mathrm{~h}$ with $100 \mathrm{nM}$ of monomeric $A \beta$ (A 3 mono) or $100 \mathrm{nM}$ of $A \beta_{1-42}$ oligomers $\left([A \beta]_{n}\right)$ then fixed and permeabilized for (immuno)staining with antiMAP2, Phalloidin, anti-actin F, and anti-Bassoon. Microfluidic chambers were analyzed by fluorescence microscopy by counting phalloidin clusters affixed to MAP2 and Bassoon on hippocampal dendrites. a. Representative micrographs of triple stained dendrites after $6 \mathrm{~h}$ in the presence (lower panel, $[A \beta]_{n}$ ) or absence (upper panel, Co.) of $A \beta$ oligomers. b-c. Quantification of dendritic spines in hippocampal neurons treated with LJ2a (b) or LJ3a (c) as indicated. Both inhibitors show synaptoprotective effects at submicromolar concentration. Histograms represent means (+/-SD) of 3 independent experiments $\left({ }^{* * *} \mathrm{p}\right.$ value $\left.<0.0001\right)$. 
Figure 8: Caspase-2 inhibitors prevent sterol regulatory element-binding protein 2 (SREBP2) activation via the inhibition of site 1 protease (S1P) cleavage.

a. Schematic representation of cDNAs encoding HA-tagged Casp2, Myc-tagged S1P at the carboxy terminus (S1P-Myc), V5-tagged SREBP2, PIDD1-Flag, RAIDD-6HIS. Intracellular S1P was detected by an S1P antibody that recognizes the first 50 AA and membrane and secreted S1P polypeptides were detected by an antibody that recognizes AA200 to AA300. b. HEK 293 cells were transfected with indicated plasmids in order to overexpress SREBP2, S1P, RAIDD, PIDD, and Casp-2. After $5 \mathrm{hrs,} \mathrm{cells} \mathrm{were} \mathrm{incubated} \mathrm{in} \mathrm{DMEM/F12} \mathrm{medium}$ supplemented with vehicle, LJ2a, LJ3a, or $\Delta 2 \mathrm{ME}-\mathrm{TRP} 601(10 \mu \mathrm{M})$ for $16 \mathrm{~h}$. Then whole cell extracts where subjected to WB to detect (cleaved) SREBP2 using an antibody directed against the V5 epitope.

TABLE 1: Caspase inhibition activity of P2-stereospecific LJ2a, LJ2b, LJ3a, LJ3b compounds against Casp-2 vs Casp-3

Casp2 Casp3

\begin{tabular}{|c|c|c|c|c|c|c|}
\hline Compounds & $\begin{array}{c}k_{3} \\
\left(m^{-1}\right)\end{array}$ & $\begin{array}{c}\mathrm{K}_{\mathrm{I}} \\
(\mathrm{nM})\end{array}$ & $\begin{array}{c}\mathbf{K}_{3} / \mathbf{K}_{\mathrm{l}} \\
\left(\mathbf{M}^{-1} \cdot \mathbf{s}^{-1}\right)\end{array}$ & $\begin{array}{c}\mathrm{k}_{3} \\
\left(\mathrm{~ms}^{-1}\right)\end{array}$ & $\begin{array}{c}\mathrm{K}_{\mathrm{l}} \\
(\mathrm{nM})\end{array}$ & $\begin{array}{c}\mathbf{K}_{3} / \mathbf{K}_{\mathrm{l}} \\
\left(\mathbf{M}^{-1} \cdot \mathbf{s}^{-1}\right)\end{array}$ \\
\hline LJ2a & $5 \pm 5 \times 10^{-4}$ & $0.9 \pm 0,1$ & 5499419 & $1.3 \pm 4 \times 10^{-5}$ & $11,5 \pm 0.9$ & 113425 \\
\hline LJ2b & $4 \pm 3 \times 10^{-4}$ & $524 \pm 10$ & 7177 & $8 \pm 2 \times 10^{-3}$ & $17498 \pm 104$ & 457 \\
\hline LJ3a & $5 \pm 7 \times 10^{-4}$ & $2.8 \pm 0.8$ & 1708996 & $0.7 \pm 9 \times 10^{-5}$ & $399,8 \pm 93,3$ & 1807 \\
\hline LJ3b & $7 \pm 10^{-3}$ & $8539 \pm 300$ & 823 & $0,8 \pm 6 \times 10^{-5}$ & $84205 \pm 13000$ & 9 \\
\hline
\end{tabular}


a.<smiles>CC(=O)NC(C(=O)N[C@@H](CN[C@H](C(=O)NC(C)C(=O)N[C@@H](CC(=O)O)C(=O)O)C(C)C)CC(=O)O)C(C)C</smiles>

Ac-VDVAD-CHO<smiles>CC(=O)N[C@@H](CC(=O)O)C(=O)N[C@@H](CCC(=O)O)C(=O)NC(C(=O)NC(CC(=O)O)C(=O)O)C(C)C</smiles>

Ac-DEVD-CHO<smiles>CC(=O)NC(C(=O)NC(CC(=O)O)C(=O)NC(C(=O)N1CCC(OC(C)C)C1C(=O)NC1CC(=O)OC1O)C(C)C)C(C)C</smiles>

c33

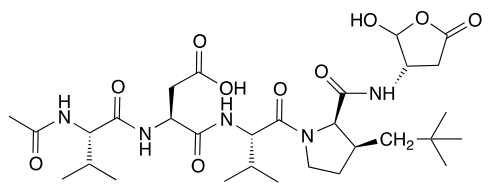

h33 b.

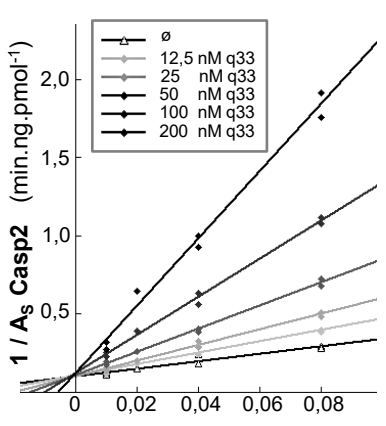

$1 /$ [AC-VDVAD-AMC] $\left(\mu \mathrm{M}^{-1}\right)$ c.

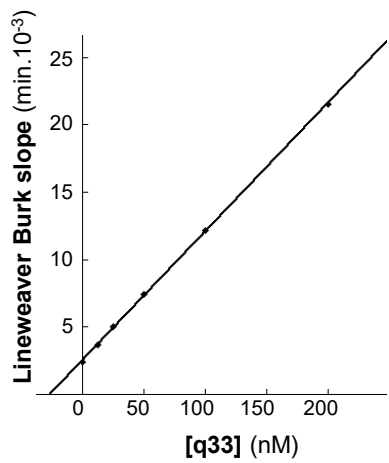

d.

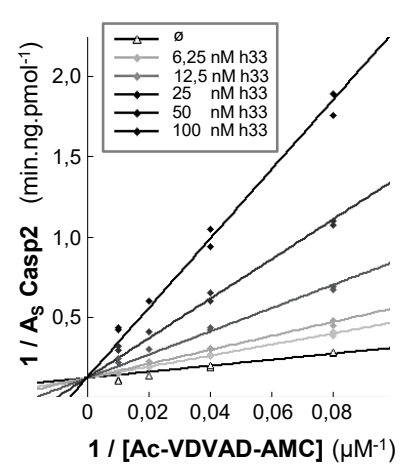

e.

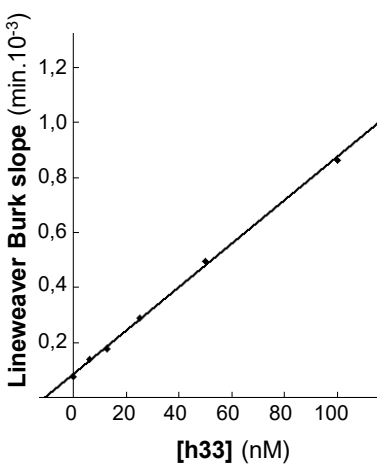

f.

Enzyme assays

\begin{tabular}{|c|c|c|c|c|c|}
\hline Compounds & $\begin{array}{c}\text { Casp2 } \\
I^{\prime} C_{50}(n M)\end{array}$ & $\begin{array}{c}\text { Casp3 } \\
\mathrm{IC}_{50}(\mathrm{nM})\end{array}$ & $\begin{array}{l}\text { Casp2 } \\
\mathrm{Ki}(\mathrm{nM})\end{array}$ & $\begin{array}{l}\text { Casp3 } \\
\text { Ki (nM) }\end{array}$ & $\begin{array}{c}\mathbf{K}_{\mathbf{i}} \text { ratio } \\
\text { (Casp3/Casp2) }\end{array}$ \\
\hline VDVAD-CHO & 7 & 7 & 8 & 6 & 0,75 \\
\hline DEVD-CHO & 3907 & 1 & 3222 & 0,2 & $6210^{-6}$ \\
\hline c33 & 271 & 6721 & 122 & 2443 & 20 \\
\hline h33 & 11 & 4573 & 10,9 & 6512 & 597 \\
\hline k33 & 178 & 1964 & 90,5 & 2772 & 31 \\
\hline q33 & 15 & 2538 & 24 & 2370 & 94.5 \\
\hline
\end{tabular}


a.
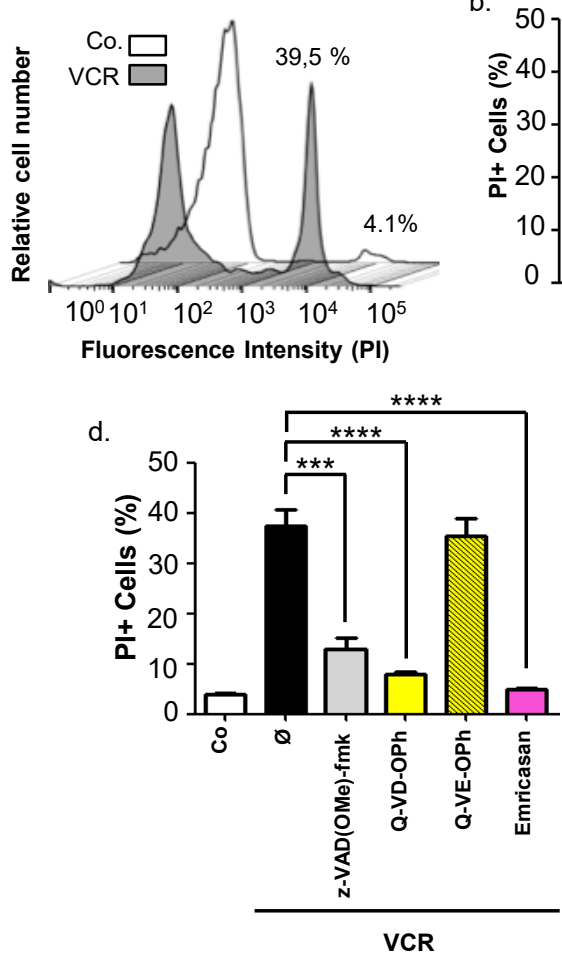

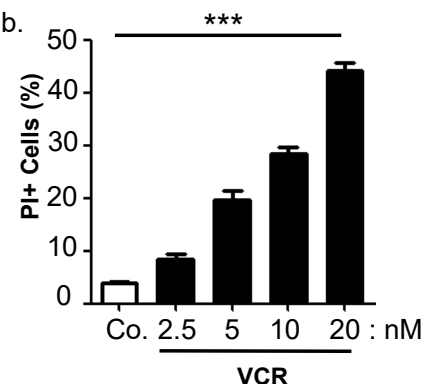

c.
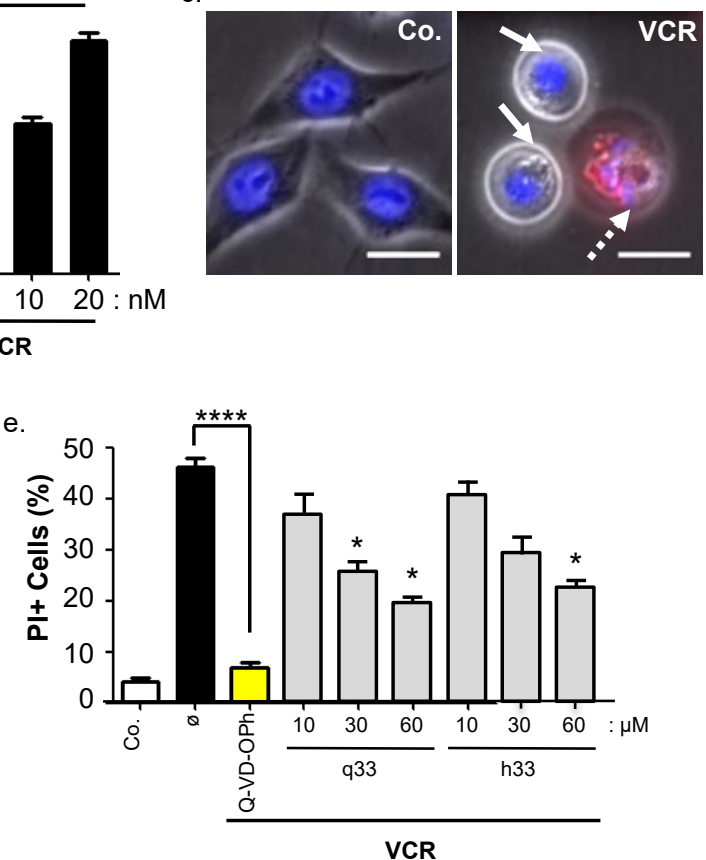

Bosc et al., 2021 Fig. 2 


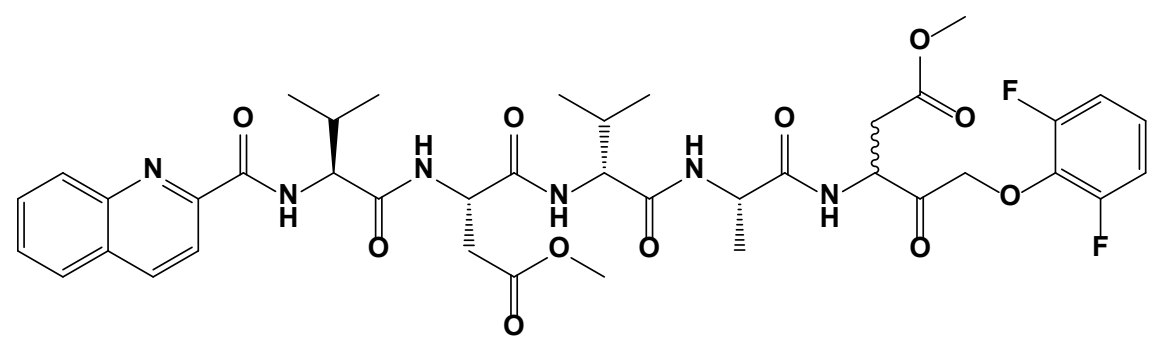

TRP-601

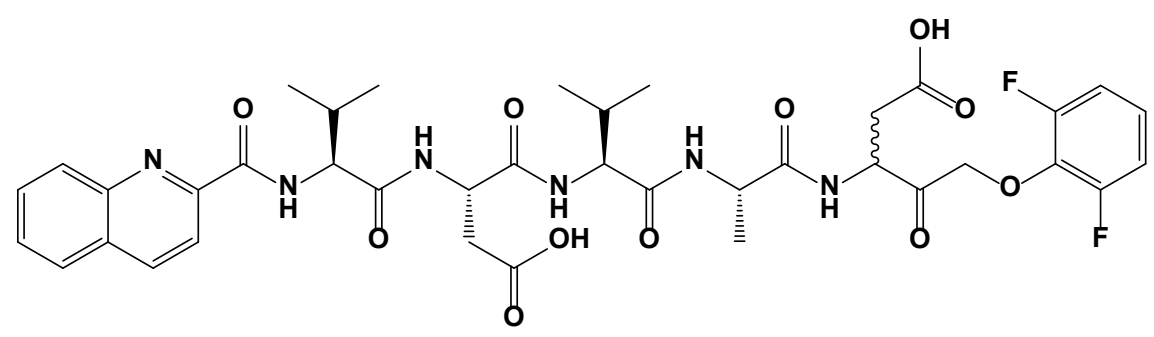

$\Delta$ 2MeTRP-601

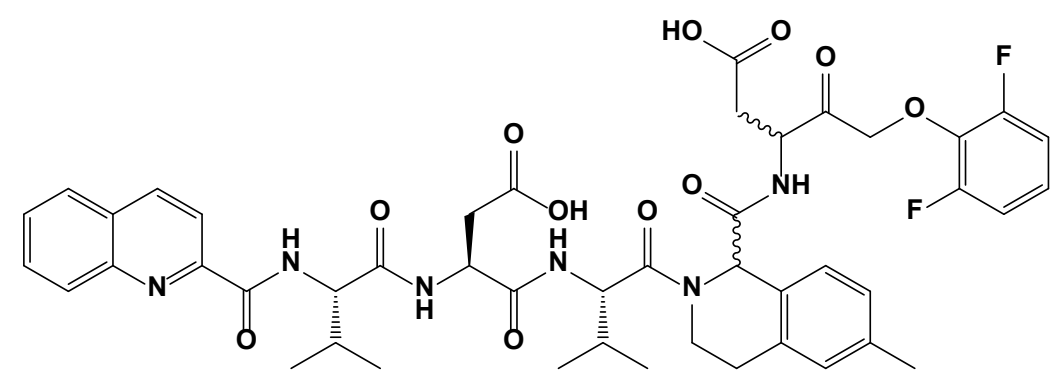

LJ2

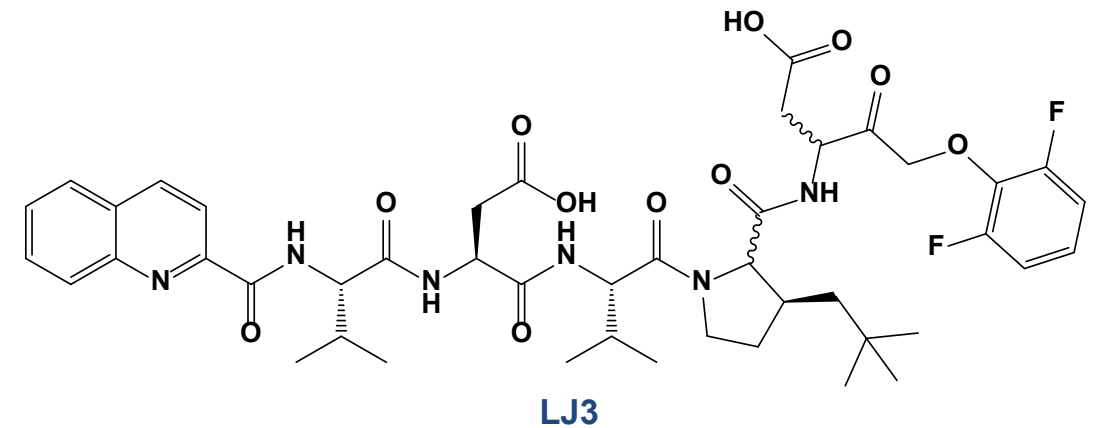

Bosc et al., 2021 Fig. 3 
a.

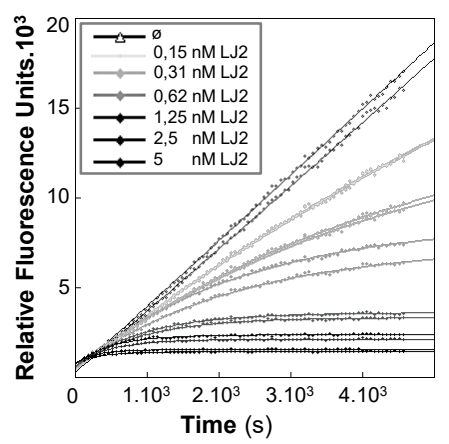

e.

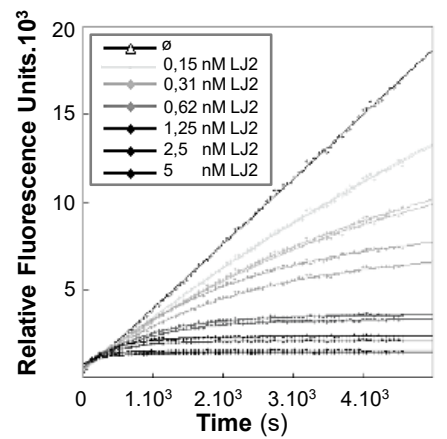

b.

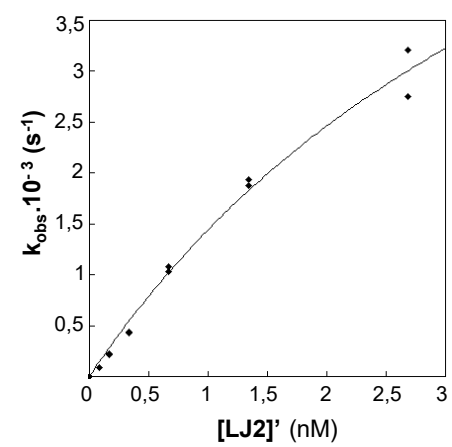

f.

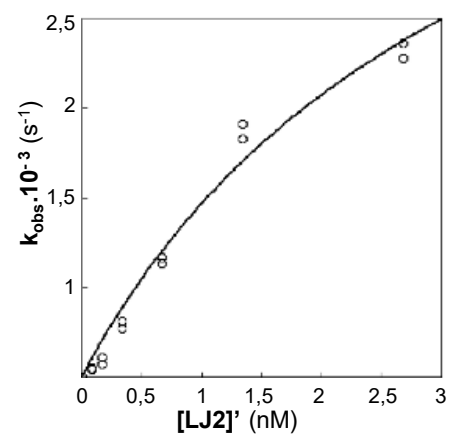

c.

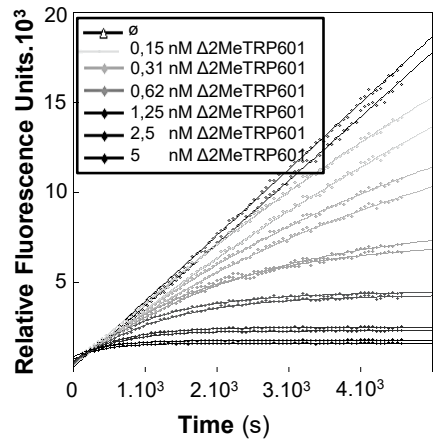

g.

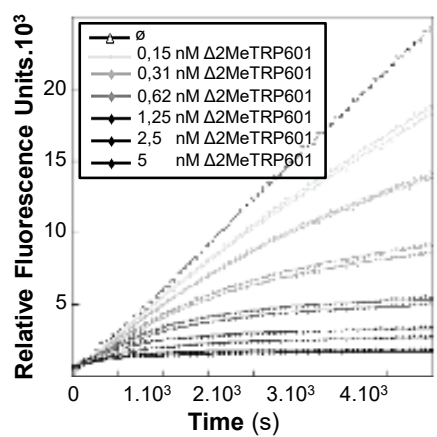

h.

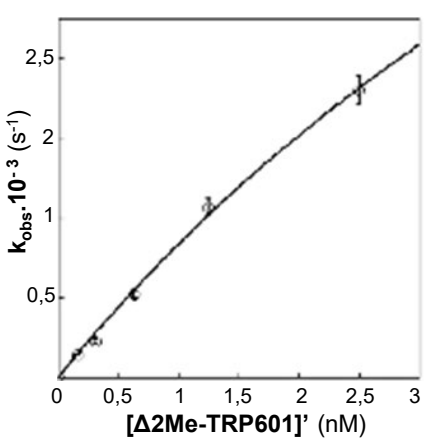

Casp2

Casp3

\begin{tabular}{|c|c|c|c|c|c|c|}
\hline Compounds & $\begin{array}{c}k_{3} \\
\left(m^{-1}\right)\end{array}$ & $\begin{array}{c}\mathrm{K}_{\mathrm{l}} \\
(\mathrm{nM})\end{array}$ & $\begin{array}{c}\mathbf{K}_{3} / \mathbf{K}_{1} \\
\left(\mathbf{M}^{-1} \cdot \mathbf{s}^{-1}\right)\end{array}$ & $\begin{array}{c}\mathbf{k}_{3} \\
\left(\mathrm{~ms}^{-1}\right)\end{array}$ & $\begin{array}{c}\mathrm{K}_{\mathrm{l}} \\
(\mathrm{nM})\end{array}$ & $\begin{array}{c}\mathbf{K}_{3} / \mathbf{K}_{1} \\
\left(\mathbf{M}^{-1} \cdot \mathbf{s}^{-1}\right)\end{array}$ \\
\hline TRP-601 & 5,56 & 377,82 & 5505 & 4,24 & 209,07 & 25126 \\
\hline$\Delta 2 \mathrm{Me}-\mathrm{TRP} 601$ & 8,08 & 5,49 & 1586020 & 1,85 & 1,17 & 1613405 \\
\hline LJ2 & 4,91 & 3,68 & 1322875 & 2,37 & 47,02 & 51992 \\
\hline
\end{tabular}

Bosc et al., 2021 Fig. 4 
a.

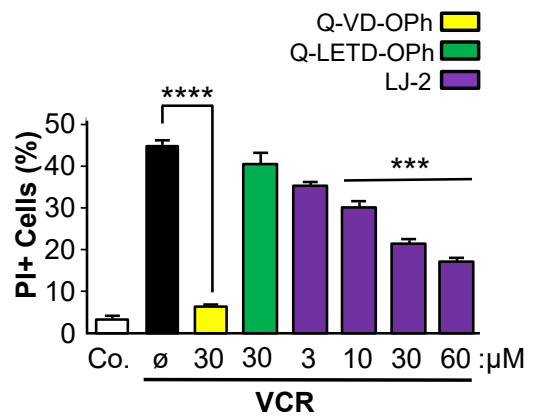

b.

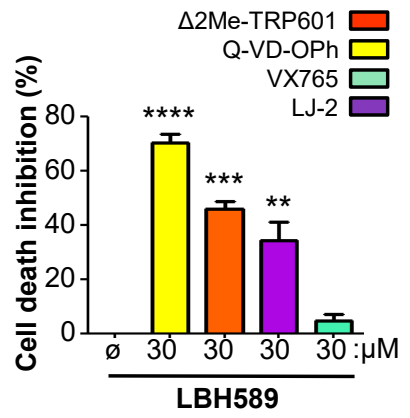

c.

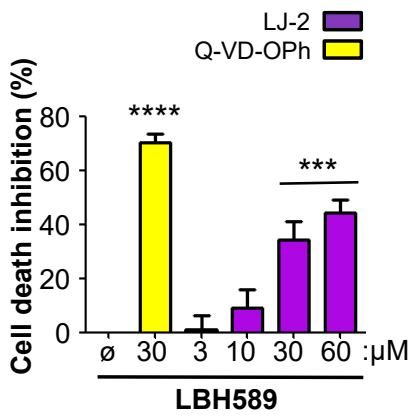

Bosc et al., 2021 Fig. 5 

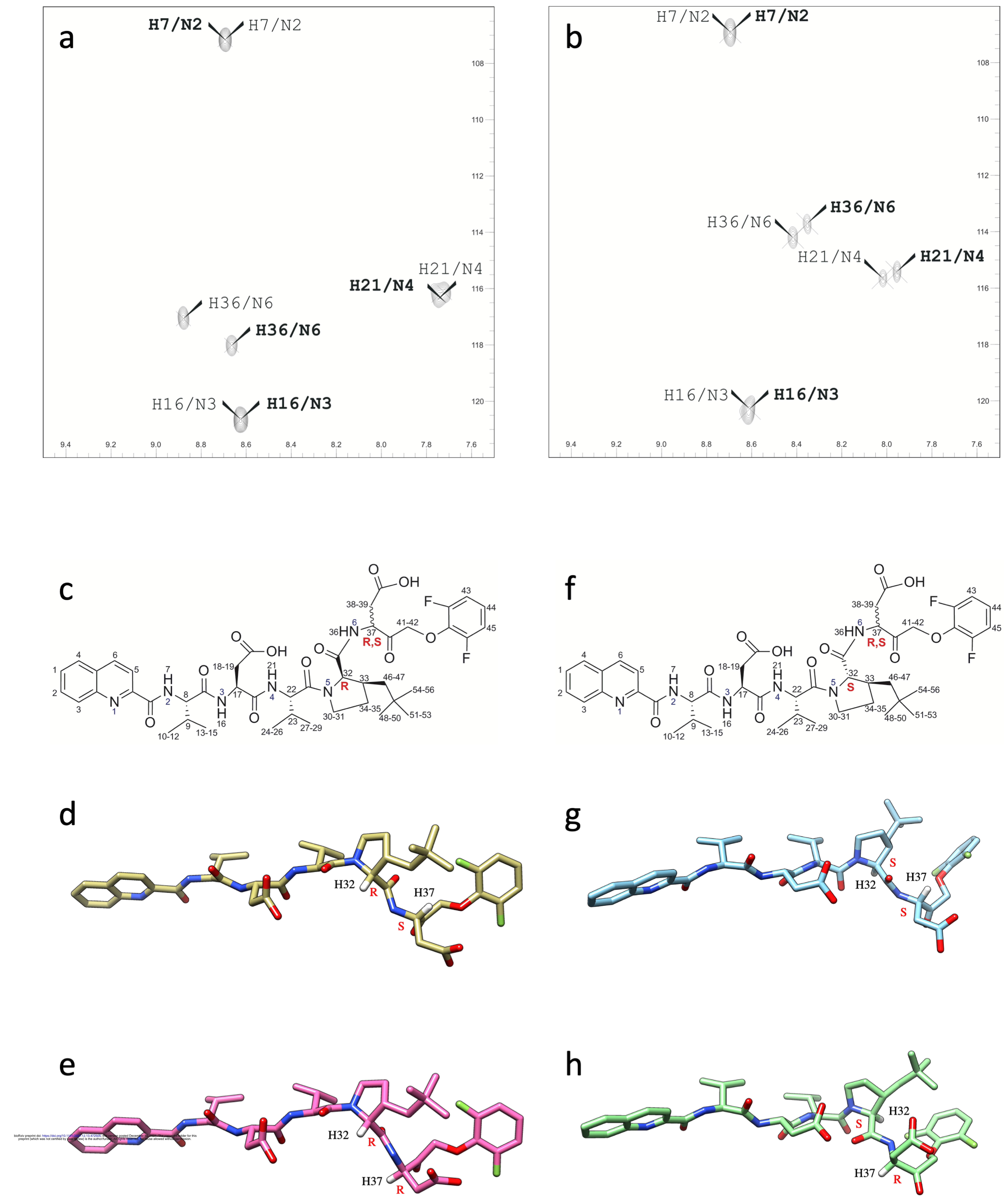

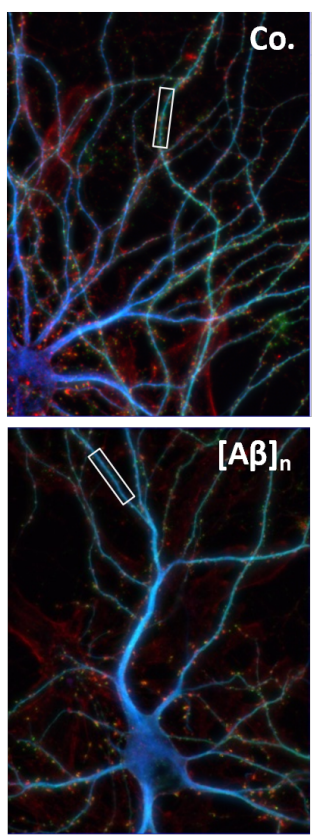

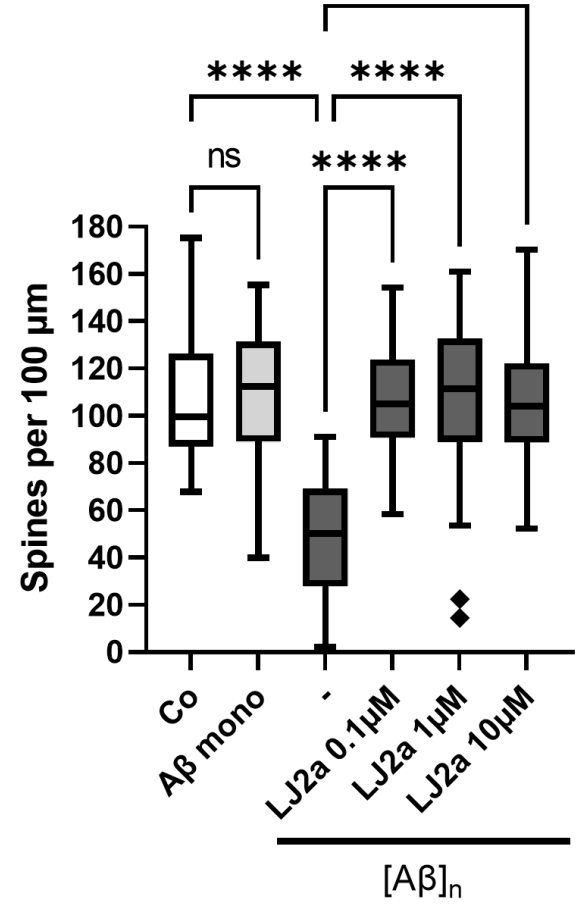

c

****

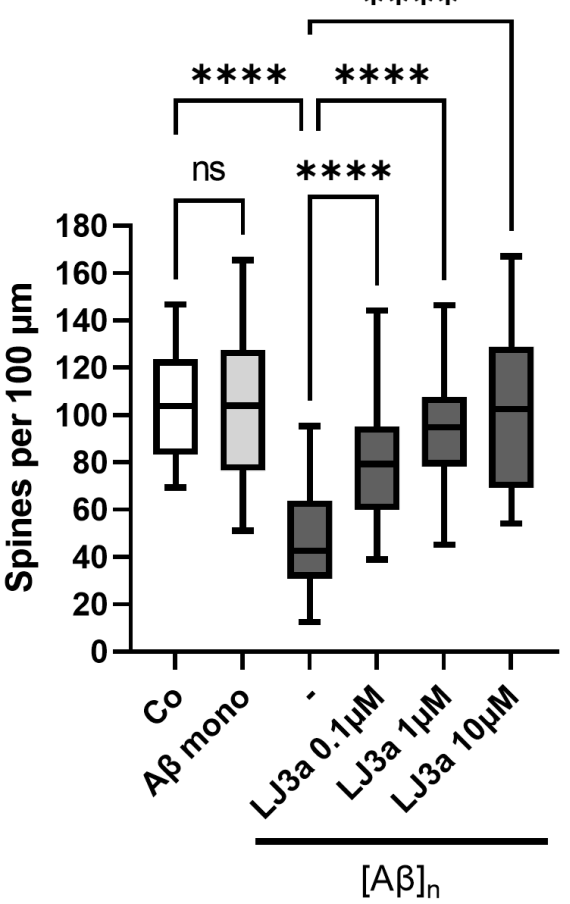


V5-SREBP2

Myc-S1P

Casp2-HA

PIDD1-Flag

RAIDD-6HIS
Veh. LJ2a LJ3a $\Delta 2 \mathrm{Me}-T r p 601$

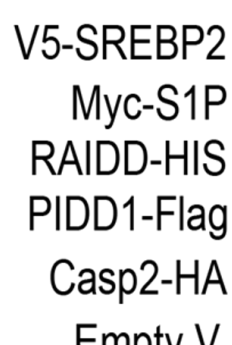

Empty V.

V5 (S.E)
V5 (L.E)

.. $0 \quad \frac{-150}{4(\mathrm{FL})}$ $6 \mathrm{HIS}$

\begin{tabular}{|c|c|c|c|c|c|c|c|}
\hline & + & & + & & + & & + \\
\hline & + & & + & & + & & + \\
\hline & + & & + & & + & & + \\
\hline & + & & + & & + & & + \\
\hline & + & & + & & + & & + \\
\hline+ & & + & & + & & + & \\
\hline
\end{tabular}

Tubulin

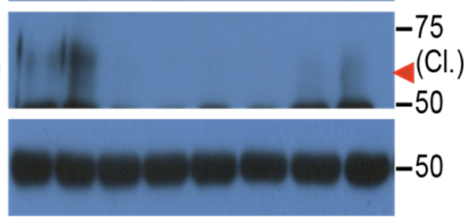




\begin{tabular}{|c|c|c|c|c|c|c|}
\hline Compounds & $\begin{array}{c}k_{3} \\
\left(m^{-1}\right)\end{array}$ & $\begin{array}{c}K_{1} \\
(n M)\end{array}$ & $\begin{array}{c}k_{3} / K_{\mathrm{l}} \\
\left(M^{-1} \cdot s^{-1}\right)\end{array}$ & $\begin{array}{c}k_{3} \\
\left(\mathrm{~ms}^{-1}\right)\end{array}$ & $\begin{array}{c}K_{\mathrm{l}} \\
(\mathrm{nM})\end{array}$ & $\begin{array}{c}k_{3} / K_{l} \\
\left(M^{-1} \cdot s^{-1}\right)\end{array}$ \\
\hline LJ2a & $5 \pm 5 \times 10^{-4}$ & $0.9 \pm 0,1$ & 5499419 & $1.3 \pm 4 \times 10^{-5}$ & $11,5 \pm 0.9$ & 113425 \\
\hline LJ2b & $4 \pm 3 \times 10^{-4}$ & $524 \pm 10$ & 7177 & $8 \pm 2 \times 10^{-3}$ & $17498 \pm 104$ & 457 \\
\hline LJ3a & $5 \pm 7 \times 10^{-4}$ & $2.8 \pm 0.8$ & 1708996 & $0.7 \pm 9 \times 10^{-5}$ & $399,8 \pm 93,3$ & 1807 \\
\hline LJ3b & $7 \pm 10^{-3}$ & $8539 \pm 300$ & 823 & $0,8 \pm 6 \times 10^{-5}$ & $84205 \pm 13000$ & 9 \\
\hline
\end{tabular}

